University of Rhode Island

DigitalCommons@URI

Open Access Dissertations

2021

\title{
TURNING POINTS: A CASE STUDY OF MOTIVATION IN FOREIGN LANGUAGE
}

Shawna C. Iula

University of Rhode Island, siula@uri.edu

Follow this and additional works at: https://digitalcommons.uri.edu/oa_diss

\section{Recommended Citation}

Iula, Shawna C., "TURNING POINTS: A CASE STUDY OF MOTIVATION IN FOREIGN LANGUAGE" (2021). Open Access Dissertations. Paper 1259.

https://digitalcommons.uri.edu/oa_diss/1259

This Dissertation is brought to you for free and open access by DigitalCommons@URI. It has been accepted for inclusion in Open Access Dissertations by an authorized administrator of DigitalCommons@URI. For more information, please contact digitalcommons-group@uri.edu. 
TURNING POINTS: A CASE STUDY OF MOTIVATION IN

FOREIGN LANGUAGE

BY

SHAWNA C. IULA

A DISSERTATION SUBMITTED IN PARTIAL FULFILLMENT OF THE REQUIREMENTS FOR THE DEGREE OF

DOCTOR OF PHILOSOPHY

IN

EDUCATION

UNIVERSITY OF RHODE ISLAND

AND

RHODE ISLAND COLLEGE

2021 
DOCTOR OF PHILOSOPHY DISSERTATION

\author{
OF \\ SHAWNA C. IULA
}

\title{
APPROVED:
}

Dissertation Committee:

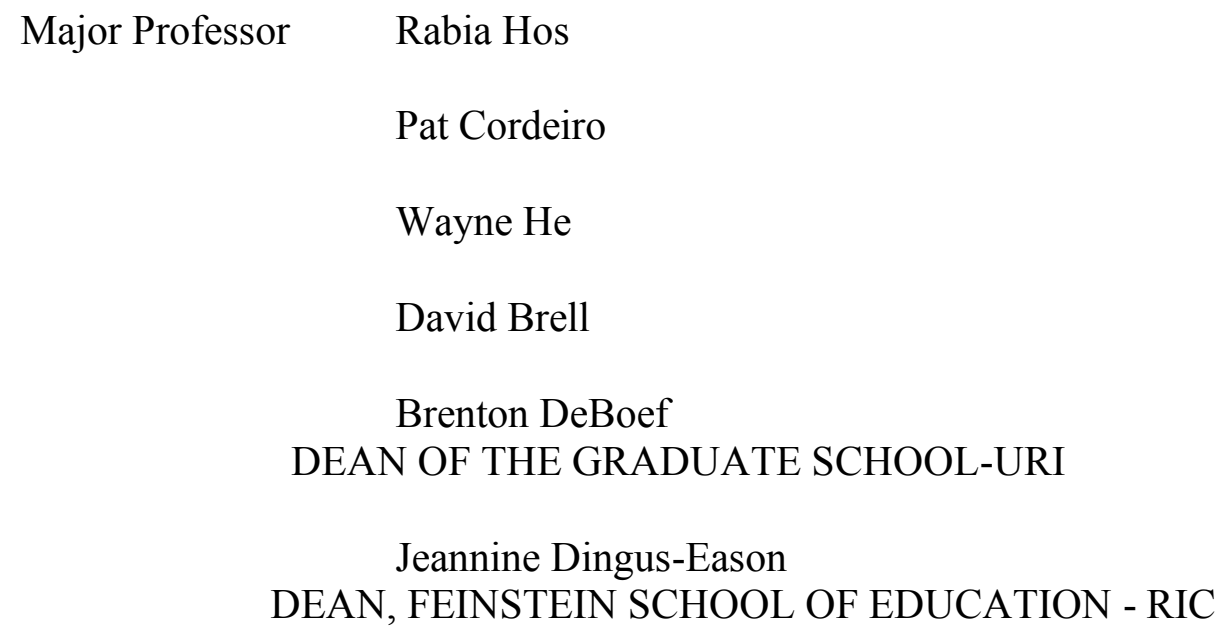

UNIVERSITY OF RHODE ISLAND

AND

RHODE ISLAND COLLEGE

2021 


\begin{abstract}
Enrollment in foreign language courses has been declining. Fewer students are studying foreign languages and those that do often discontinue after the introductory levels. This single-embedded case study looks into why students who initially wanted to continue on to more intermediate levels did not, and also why students who initially only wanted to complete introductory levels changed their plans and continued on to more intermediate levels. Participants included two groups with nine participants total. The first group consists of five students who initially planned on discontinuing after introductory levels and changed their minds and decided to continue. The second group consists of four students who initially planned on continuing onto intermediate level courses but changed their plans and decided not to continue.

Multiple sources of data were used. The first was a participant interest form, the second was three words that summarized what influenced their decision, the third data source was semi-structured interviews, and the fourth was a researcher journal used for memos.
\end{abstract}

Results of the non-continuing students indicate that most are still interested in learning the language but were deterred by the course structure, such as time commitment and by not making meaningful progress. Results of continuing students show that a newfound sense of confidence and making meaningful progress influenced their decision to continue, in addition to being motivated by career plans, situations in which they could apply the language, and by support from family, peers or faculty. Implications include 
suggestions for instructors and administrators on how to use these results to motivate their students. 


\section{ACKNOWLEDGMENTS}

Well, one pandemic and one baby later, this dissertation is complete. What a year.

First, I would like to thank my major professor, Dr. Rabia Hos for her guidance and support throughout this process. In particular, her always helpful suggestions and encouragement that made this research more robust and impactful. I would also like to thank the rest of my committee, Dr. Pat Cordeiro, Dr. Wayne He, and Dr. David Brell. I could not have had a more supportive group. I am also thankful for all of the professors I have had in this program, whose feedback on my writing pushed me to get to this point.

Additionally, I would like to thank the 2016 cohort. We had some great discussions in our classes and hearing everyone's thoughts on the various intense and complex topics we learned about was insightful and helped enrich my own thinking. It's been great to go through this with you all!

Personally, I need to give a big thanks to my husband, Mike, who was always supportive throughout these five years. Not only was he encouraging, but also assumed a big share of baby and household duties to ensure I had time to study and write this dissertation. To Michael III, my favorite little distraction, who was born right after data collection: Thanks for going to bed early to give me time to write this dissertation! I hope I can make you proud!

I also need to recognize and thank the hard-working graduate women who came before me, paving the way and making it possible for me and other women to earn a $\mathrm{PhD}$. One of those women is my mother, who has been an ideal role model and a great 
support, not to mention a great person to talk to who knows of the struggles of graduate school.

Any thanks I give regarding education would not be complete without mentioning my late grandfather, whose goal was to live to see his grandchildren graduate from college. Well, look at me now Papa, I am about to earn a PhD! 


\section{TABLE OF CONTENTS}

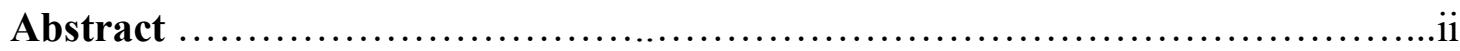

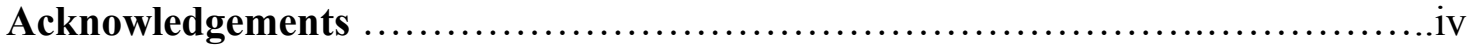

Table of Contents..................................................................

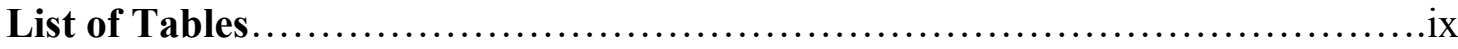

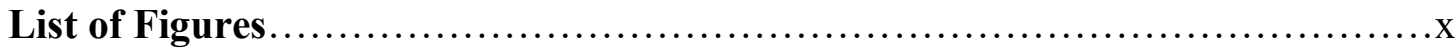

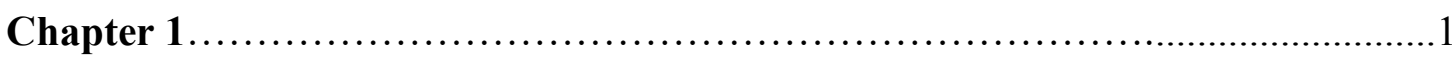

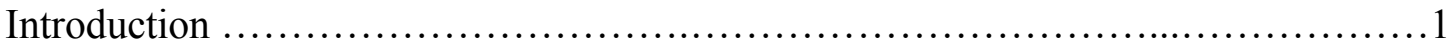

Significance of Study and Research Question..................................6

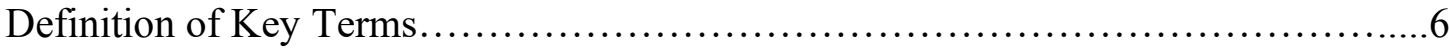

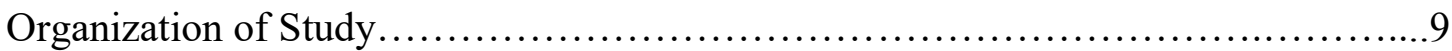

Chapter 2 Review of Literature............................................ 11

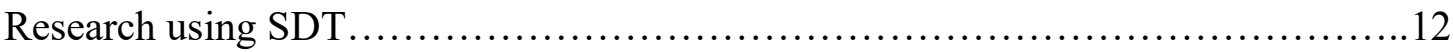

Socio-Educational Model.......................................................13

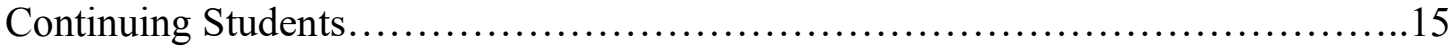

Non-continuing Students-Attrition in Foreign Language Studies......................23

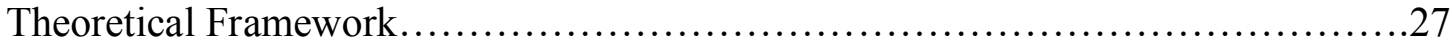

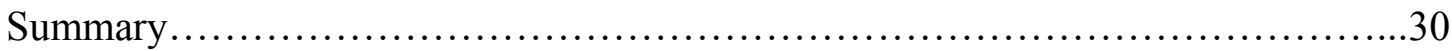

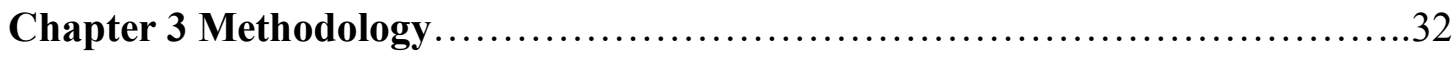

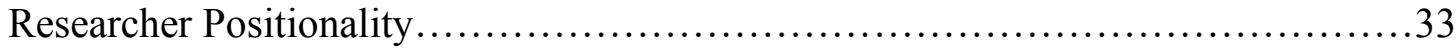

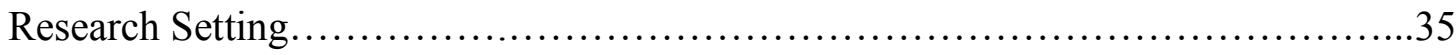

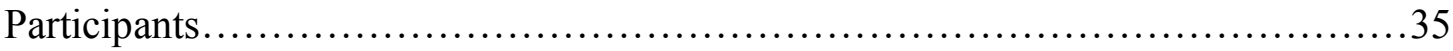

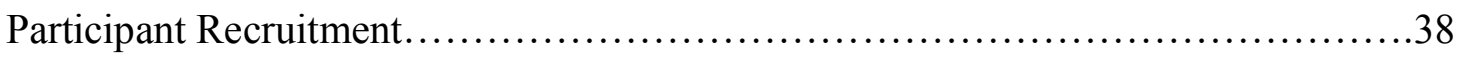




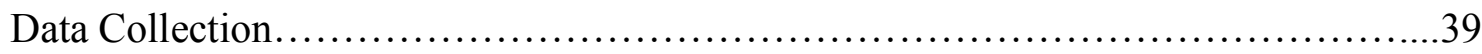

Data Analysis.........................................................41

Ethical Considerations.................................................44

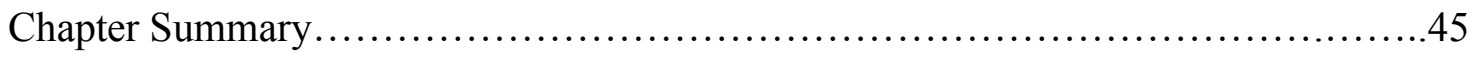

Chapter 4 Findings........................................................ 46

Summary of Each Group..................................................49

Findings in Non-Continuing Student Group................................49

Findings in Continuing Student Group......................................60

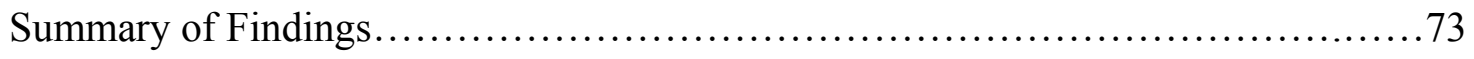

Summary of Participants................................................ 74

Chapter Summary...................................................... 81

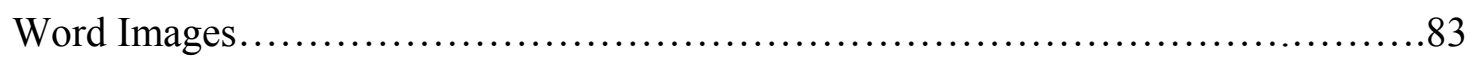

Chapter 5 Discussion............................................... 85

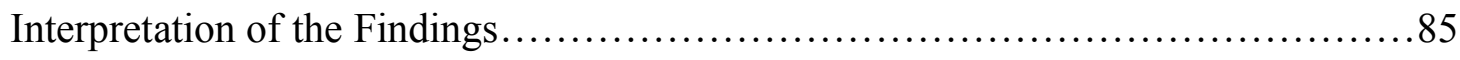

Implications........................................................ 92

Recommendations to Administrators..................................... 93

Recommendations to Instructors....................................... 98

Future Research........................................................ 106

Appendices.......................................................... 108

Appendix A: Chart of Embedded Case Study, Single-Case, Multiple Units of

Analysis......................................................... 108

Appendix B: Interview Protocol....................................... 109

Appendix C: Email to Instructors to Recruit Students In-Class..................111 
Appendix D: Email to Instructors of Student Recruited Post-COVID via Email......113 Appendix E: Email to Students Who Were Recruited Post-COVID via Email........115

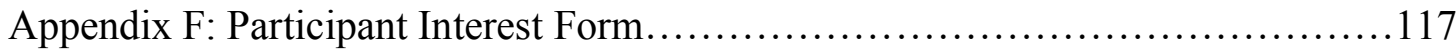

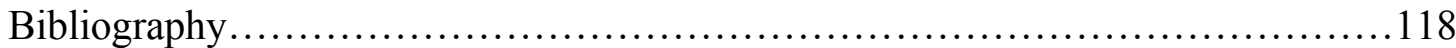




\section{LIST OF TABLES}

TABLE

PAGE

Table 1. Continuing Participants ................................................. 30

Table 2. Non-continuing participants............................................. 30

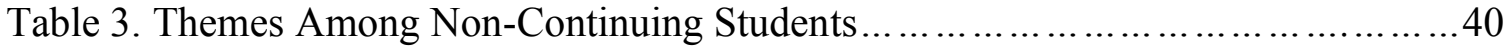

Table 4. Themes Among Continuing Students ..........................................41

Table 5. Recommendations for Policy and Practice............................. 105 


\section{LIST OF FIGURES}

$\begin{array}{ll}\text { FIGURE } & \text { PAGE }\end{array}$

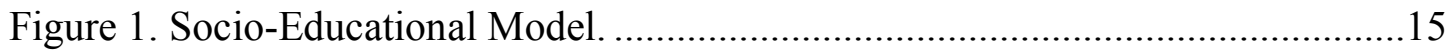




\section{CHAPTER 1}

\section{INTRODUCTION}

U.S. higher education institutions overall have had a steady decrease in students enrolled in language courses. Starting in 1998 there was a steady increase in

foreign language enrollment, until 2013, where overall enrollments dropped by $6.7 \%$. This trend continued, and between 2013 and 2019 enrollments dropped another 9.2\% (Looney et al., 2018). When the overall educational trajectory is viewed, it suggests that only a small proportion of K-12 students study foreign languages and even fewer persist. In 2017, for example, the percentage of K-12 students studying a foreign language was 20\% (Devlin, 2018), and in 2016 the percentage of students at postsecondary institutions enrolled in a foreign language was even lower at $7.5 \%$ (Looney et al., 2018). In contrast to international comparisons, a median of $92 \%$ of European students study a foreign language in elementary and post-secondary schools, with some countries, such as Luxembourg, Malta, and Liechtenstein, having an average of $100 \%$ (Devlin, 2018). Devlin also noted that learning two foreign languages is a requirement in more than 20 European countries, thus it is evident that these high rates are not solely due to English being the lingua franca.

With this small percentage of American college students studying a foreign language, it is important to review the current trends in foreign language requirements. Over the past decade, in 2009, 2013, and 2016, there was a 5:1 ratio of 
students in introductory to advanced language courses, which is likely reflective of language requirements (Looney et al., 2018). This means that most students who study foreign languages will obtain only an introduction to a language but will not participate in advanced language study and, as such, are not likely to gain significant proficiency. The consequence of this is that students frequently leave college with no or only introductory foreign language abilities.

One may wonder why the number of students graduating from college as monolingual would be an issue. Many people are able to have successful careers without learning foreign languages. However, the same could apply to earning a higher education degree; many people have successful careers without one, but there are many more opportunities with one. The U.S. demand for bilingual workers has nearly tripled in five years, going from 240,000 in 2010 to 630,000 in 2015 and has been increasing since. This demand was not only for speakers of Spanish but for any language because of the increased opportunity for the employer to serve a wider range of customers (New American Economy, 2017). These data reveal that, although it is possible and even common for graduates to gain employment without being multilingual, it substantially increases opportunities for meaningful employment in an increasingly more global society.

In addition to the benefit bilingualism brings to workers seeking employment, the American Council on the Teaching of Foreign Language (ACTFL) states that there are also many cognitive benefits as well, including enhanced problem-solving skills, memory function, creative thinking ability, and improved attitude toward the target language and culture (defined as the language and culture the student is studying) 
(Benefits Language Learning, n.d.). One could argue an even more beneficial outcome of learning languages is the improved attitude toward the target culture and its effect on one's tolerance and its positive effect on xenophobia.

In 2016 the United Nations' (2016) General Assembly proclaimed that xenophobia and racism had been increasing globally. The following year, 2017, marked the first time in over a decade that the number of reported hate crimes exceeded 1000 in the United States in one year, with the majority targeted at immigrant populations (Levin et al., 2018). With the COVID-19 pandemic, 2020 has seen another increase in xenophobia as migrants and people of Asian descent experienced an increase in verbal and physical assaults, along with stigmatization for spreading the virus (Department of Global Communications, 2020). Such prejudices affect more than just political policies but also go so far as to be associated with higher mortality rates among all non-white American citizens, even those not in the targeted group (Morey et al., 2018). Moreover, the World Health Organization has reported that stigma can prevent people from seeking care when they are ill in order to avoid discrimination (Department of Global Communications, 2020).

The vastness and complexity of these issues require much more than a simple fix. However, one small aspect that can be a part of a bigger solution is an increase in Americans who study foreign languages. Foreign language acquisition has been shown to increase people's cross-cultural understanding, make people more open to new things, and improve tolerance to diversity (Gojkov-Rajić et al., 2013). The extent to the positive effect of learning foreign languages should not be ignored. Students who studied a foreign language were not only more open to the target culture, but they 
were also more open to cultures outside of the ones they studied (Gojkov-Rajić et al., 2013).

Despite these employment, cognitive, and social benefits, U.S. higher education institutions have had a steady decrease in students enrolled in language courses, and the reasons as to why are unclear (Looney et al., 2018). There are also students who may have intended on continuing language courses but then discontinued after their beginner-level courses were completed. Conversely, there are also students who go beyond their general education or major requirement and take advanced courses even when their intention was only to complete their minimum requirement.

What is currently lacking in research is the change in motivation that leads to continuing or discontinuing foreign language studies. The research conducted has given great insight into the motivation of intermediate or advanced students, such as college seniors majoring in a foreign language (Awad 2017; Tsang, 2012).

Additionally, there has been research on why K-12 students may discontinue language studies or immersion programs and why adults may discontinue part-time language programs (Gibson, et al., 2007; Wesely, 2010). However, these studies do not include beginner-level students who are the majority of higher education students enrolled in foreign language courses (Looney et al., 2018). Moreover, if the majority of university students studying a foreign language are within the first two semesters and then do not continue, this research does not show what should be emphasized in the semesters when universities have the most students enrolled and who have not yet made the decision to continue. 
Furthermore, the research that has been conducted on continuing students was with students far beyond the time period when they initially made the decision whether or not to continue. If participants are in advanced studies, it has been semesters or even years since they made their decision to continue. This is a crucial factor to consider, as motivational research in foreign languages has shown that timing is one of the most important factors when gaining information on motivational factors (Dörnyei, 2001). This means one can give more depth in reasoning for making a decision if it is a current issue or recent choice than if the decision was made years in the past and is no longer directly relevant.

In order to gain a more accurate understanding of students' decision to continue or discontinue foreign language studies, it would be beneficial to focus on students who decided not to continue when they initially planned to continue and also to focus on students in their first voluntary language course when they have just made their decision to continue. Research questions must examine variations the participants may have had throughout the course or semesters, thus addressing the ebb and flow of motivation levels, which as Dörnyei (2001) states, are present even within a single course.

This study contributes to motivation and foreign language literature by offering a qualitative understanding of participants who have changed their trajectory after completing beginner-level courses. The first two semesters are the most-enrolled foreign language courses and are often the last foreign language course students take (Looney et al., 2018). The research questions are directed toward an understanding of what influences students to make their decision and may provide insight into what 
institutions and instructors can do and what psychological aspects institutions and instructors can nurture to retain their students and help them develop into multilingual, multicultural graduates.

\section{Significance of Study and Research Question}

The purpose of my study was to explore the experiences of beginner language students to gain insight into what occurs during their courses that influences and motivates them to continue or discontinue their language courses. The significance of this study is the focus on the change in student plans to continue or discontinue their language studies. Previously, the research conducted in this area so far either focused on intermediate or advanced students, such as college seniors majoring in a foreign language, or on K-12 students or adult students (Awad 2017; Tsang, 2012; Gibson et al., 2007; Wesely, 2010). However, this dissertation focuses on these beginner-level students who are the majority of higher education students enrolled in foreign language courses (Looney et al., 2018). This research fills the gap and explores what could be done during the semesters when universities have the most students enrolled and who have not yet made the decision to continue or not. Therefore, my main research question was:

Research Question: Why do students change their intended language study trajectory after completing introductory courses?

\section{Definitions of Key Terms}

\section{Beginner-level Courses/Introductory-level Courses}

Higher education foreign language courses that are the first or second semester-level of language studies. 


\section{Career}

Career refers to the future career the students project they may have after graduation.

\section{Confidence}

This refers to the confidence students have in their ability to learn a language or whether they see themselves as someone capable of learning a foreign language.

\section{Continue}

Continue/continuing in this context refers to being enrolled as a student in a foreign language course for which the student will receive credit.

\section{Course structure}

Course structure may refer to a number of factors pertaining to how a course is designed for the students. This may be the amount of homework assigned, the type of assignments or the frequency of due dates.

\section{Desire to Apply Course Topic or Language Application}

This is the desire to apply their foreign language ability to a specific act, conversation or job. In the literature review I discuss the motivating aspect of wanting to apply various course topics to real-life situations.

\section{Identity}

This refers to how the students see themselves as language learners or their identity with their nationality. For example, as monolingual or multilingual people.

\section{Motivation}


The key construct in my study was motivation. Dörnyei (2001) states that researchers often disagree on the definition of motivation or if it even can be defined at all. He does, however, list aspects that most researchers do agree on. For the purpose of this study, motivation is defined in those terms; namely, the choice of a particular action, in this case to learn a second language, the persistence with it, and the effort expended on it (Dörnyei, 2001).

\section{Non-continuing/Discontinue/Not Continue}

A non-continuing student or to discontinue/not continue in this context refers to a student no longer being enrolled in a foreign language course for which the student will receive credit.

\section{Progress}

This refers to the students' sense of having made meaningful progress in a course and having achieved some amount of success in learning the language.

\section{Support}

Support is the encouragement, approval or assistance from family, friends, peers or instructors.

\section{Time}

This is a specific aspect of course structure that refers to the time commitment a course takes or the time a student is able to or not able to dedicate to a course.

\section{Chapter Summary}

I began this chapter with a discussion of the problem that led to this dissertation, namely, the decrease in enrollment in foreign language courses and the 
trend of students taking introductory courses and then discontinuing. I provided a brief description of what is lacking in the existing research and described what this dissertation offers to fill that gap in the literature. I then provided the research question and definition of key terms.

\section{Organization of Study}

This dissertation is organized into five chapters. Chapter one includes a summary of the problems that inspire and influence this study. This includes the introduction, the statement of the problem, the purpose of the study, the research question, the definition of terms, a summary of the chapter, and the organization of the study.

Chapter two is the literature review. This includes a background of the theoretical framework and studies that apply the theoretical framework. This chapter also includes a literature review on studies that are relevant to this study, specifically, research that pertains to prominent themes pertaining to this study. Moreover, it provides an overview of what research has yet to be done and what gap in the research this study is trying to fill. I additionally discuss the importance of this study and summarize the chapter.

Chapter three describes the process I used to collect, analyze, and interpret the data. I provide a description of the rationale for the methods used. Specifically, I describe why a qualitative case study was the most beneficial approach to obtain the required data and results. A description of my history as a language student and language instructor provides positionality for the reader to understand my background 
and how it may have influenced the study. I describe the details of the setting for the study and the recruitment process. I provide brief descriptions of the participants, which groups they fall into, and what their language is. I then provide descriptions of how the data was collected, analyzed, which methods were used to increase reliability, and how the data was coded.

Chapter four is a discussion of the findings of this study. I first discuss emergent themes from the group of non-continuing students that included a desire to continue with a different format, issues with course structure, issues with time commitment, and a lack of progress. I then discuss the emergent themes from the continuing students, namely identity as a Language Learner and idolizing speaker, their future career, language application, support, and progress.

Chapter five includes the discussion and concluding remarks based on the findings presented in chapter four. I provide recommendations to instructors and administrators to address each of the prominent themes, including course structure, time, confidence/identity, progress, self/relatedness, and career. I additionally discuss recommendations for future research and concluding thoughts. 


\section{CHAPTER 2}

\section{REVIEW OF LITERATURE}

This chapter provides a review and discussion of research conducted in relevant areas pertaining to this dissertation. I begin this chapter with a section reviewing research conducted that uses Self-Determination Theory (SDT), which is the theoretical framework for this study. In order to gain insight into students' choices, a background in motivation theories is beneficial to provide insight into what psychological supports are influential in this decision-making process. Therefore, I review various motivation theories.

I then divide the sections by research on students who continue on to advanced levels, including specific sections based on the results of this dissertation, such as support, autonomy, progress, confidence in ability to learn, career, and desire to apply the subject. This literature pertains to a variety of foreign languages with a focus on those in higher education. This is followed by an outline of research on students who discontinue language studies, including the limitations in the applicable research on student attrition, or non-continuing students, in a foreign language. I provide an outline of literature on attrition in foreign language studies and what influences these students to discontinue. The research on attrition is limited in higher education and tends to focus on K-12 students. Because of this, I will address those differences and link the similarities of students' experiences in K-12 to higher education. I then describe the significance of this study, including a description of the gap in the 
literature and how this study helps fill that gap. Finally, I describe the theoretical framework for this study, which is Self-Determination Theory. The purpose of this is to describe the theory and how it pertains to this study. In addition to SDT, I will describe aspects of Bandura's (1994) Self-Efficacy Theory (SET) that are utilized in this study.

\section{Research Using SDT}

Research conducted that applies SDT to language learning is divided into a number of categories. One such category has emerged as studies that summarize the three aspects of the theory; namely, autonomy, competence, and relatedness. The goal of such research is to provide insight for instructors or others to interpret and apply the theory as they see fit or to provide examples (Jones et al., 2009). Another prominent category of research is studies that look into how SDT can be applied to pedagogical methods with the specific goal of increasing students' intrinsic motivation. This research focuses on providing examples to instructors on how to increase student autonomy, which tends to increase intrinsic motivation (Davis et al., 2018; Noels, 2003).

Research on increasing student autonomy has produced recommendations such as decreasing unnecessary classroom restraints and increasing opportunities for students to make choices (Jones et al., 2009). An example of an activity recommended by Jones to increase student autonomy while practicing the past tense includes having students create Play-Doh objects of something meaningful in their past, write in the past tense why that object was meaningful, discuss it with their partner, and then tell the instructor something they learned about their partner. In each of these stages, the 
students were in control of some aspect. The instructor gave them high levels of autonomy in a number of stages in the activity, from which object they made to how much information they shared.

The example above provides a specific activity for the reader to borrow. Such examples are provided with the overarching goal of applying those activities to increase student autonomy. Although there are other psychological needs in SDT, such as competence and relatedness, research on SDT pertaining to foreign languages shows an overall focus on increasing student autonomy with the goal of then increasing intrinsic motivation.

Moreover, research focusing on autonomy has shown that student autonomy is directly related to the actions and behavior of the instructor (Noels, 2003). Specifically, that students who perceived the teacher as "controlling" had decreased self-perceptions of autonomy, and those who perceived their teacher as "informative" had higher self-perceptions of competence (Noels, 2003). Both autonomy and competence are important factors in motivation, thus, informative and non-controlling instructors have an increased chance of motivating students.

SDT has shed light on a wide range of motivational topics in education. Additionally, there are some other models that incorporate additional important factors that influence motivation. Now, I will discuss the Socio-Educational Model.

\section{Socio-Educational Model}

Gardner (2010) developed a conceptual model to determine which variables are associated with language learning, called the Socio-Educational Model. This conceptual model states that achievement in a foreign language learning is enhanced 
by prior achievement and motivation. It goes on to establish specific components that contribute to foreign language learning, such as intelligence, language aptitude, situational anxiety, and motivation. These components may lead to formal language training, informal language training or both. The ones that lead to both contribute to a higher outcome for language learners. Gardner (2010) created this model after seeing how some students of French felt they had the ability to communicate successfully in French, whereas others with the exact same course history did not think they had the ability to successfully use French. He, therefore, concluded that variations in course instruction, pedagogy methods, and the instructor could not be the only determinants for student success. Although Gardner did not apply an SDT frame, his findings connect to the competence factor of SDT. Some students did not think they could use French successfully, and since being successful and making progress fulfills the competence need, this motivational need was not met.

Following his observation of French students and their confidence in their ability, Gardner (2010) hypothesized that this variation was due to the students' identification with the language either as simply another academic course or as a means of communicating with different people. Therefore, the students' attitude toward the target culture likely affects how well they can incorporate the behavior patterns of that culture (Gardner, 2010). The students with this internal motivation to incorporate aspects of the target culture seem to receive reinforcement for class participation, whereas the student without this integrated motivation may experience the language learning process as punishment (Gardner 1974 as cited in Gardner 2010). Please see Figure 1 below for his model of this process. 
Figure 1.

Gardner's Socio-Educational Model (Gardner, 1979, as cited in Gardner, 2010)

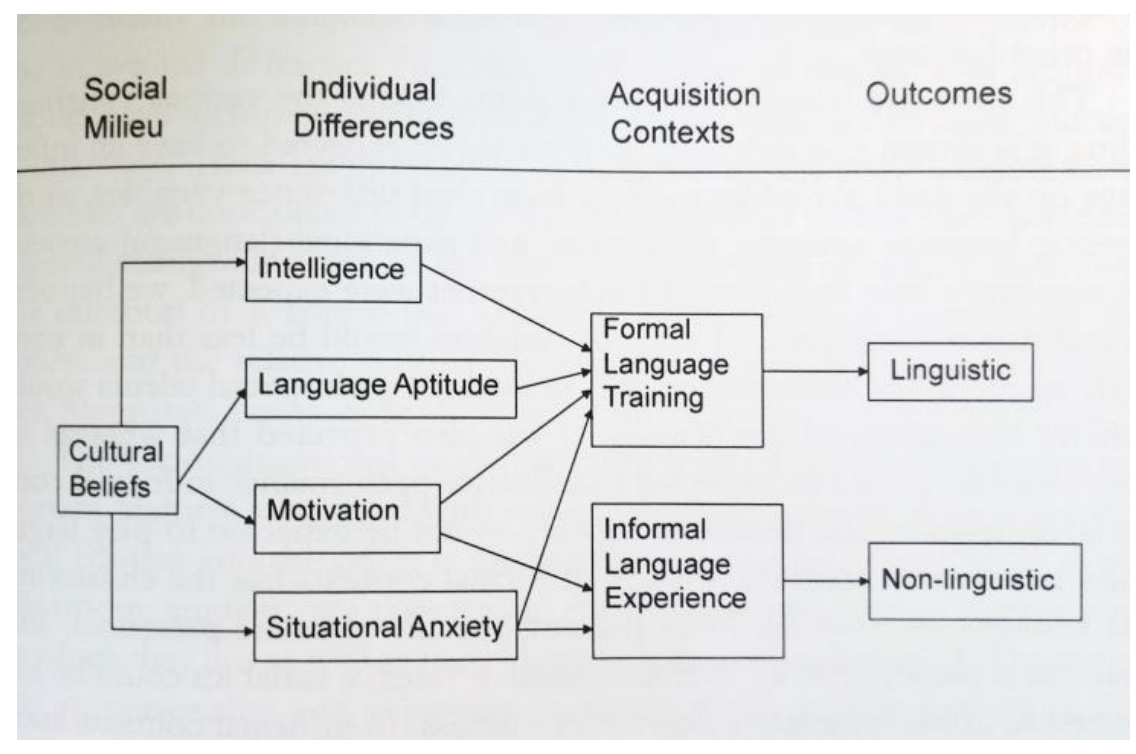

This figure shows the Socio-Educational Model and how aspects in social milieu lead to a set of individual differences, which in turn influence how a person may study or learn a language. These ways of learning the language, or acquisition contexts then have the outcome of linguistic progress, meaning skill or knowledge developed in the language, or non-linguistic progress, meaning any affective reaction to either language acquisition context (Gardner, 2010).

Gardner's work influenced the exploration of motivation in students who continue their foreign language studies. I will now discuss this and other research relating to motivation and continuing students.

\section{Continuing Students}

This section will focus on research pertaining to one of the participant groups, namely, students motivated to continue foreign language studies, followed by a section 
focusing on non-continuing students. When reviewing studies conducted on the motivation of foreign language students, how authors use the term "motivation" varies greatly. As previously noted, Dörnyei (2001) stated that the definition of motivation and how researchers use this term is contentious. Researchers often disagree on its definition or if it even can be defined at all. He does, however, list aspects on which most researchers do agree. For the purpose of this study, motivation will be defined in those terms; namely, the choice of a particular action, in this case to learn a second language, the persistence with it, and the effort expended on it. There will also be a primary emphasis on studies that have focused on the aspect of continuing in language learning.

This section is organized by subheadings that detail research on specific aspects that the literature review found to contribute to students being motivated to continue foreign language studies. These sections are: support, autonomy, progress, confidence in ability to learn the language, career, and the desire to apply the subject to real-life situations. I will now review research on support and its relation to motivation.

\section{Support}

Given that support is a factor in SDT, and that it was also found to be an important motivational factor in this dissertation, I will provide a review of studies on the role of support in motivation. Previous studies (Awad, 2017; Tsang, 2012), have shown that motivation of intermediate to advanced foreign language students is due to a range of motivational factors, such as support, the instructor's role, curriculum content, and progress. 
Awad (2017) studied motivation and persistence among advanced foreign language students. In this study, motivation was defined as the arousal of certain behaviors directed toward the accomplishment of certain tasks and persistence in exerting efforts that target task achievement. Participants in this qualitative study were 16 undergraduate and graduate students in each advanced level of Arabic, Chinese, French, and Spanish. All of the participants were in courses beyond the level required by their program and had also studied their respective language in high school. Findings showed a range of motivational factors, such as engagement in the learning process, various types of support, instructor's role, and curriculum content. Students' goals and early exposure to the language were also shown to have an influence on their decision to continue language studies. All participants cited some form of support as motivating them to continue their language studies. Much of this support came from family, for example, parents who supported their child studying abroad, traveling in the target country or going to restaurants with owners who spoke the target language. This support may also come from other students, such as tutors or conversation groups. Support as a key factor in motivation connects back to the category of relatedness in SDT. Students feel like they are being cared for by others and supported in their pursuits, which is a vital factor of relatedness (Ryan et al., 2017).

This study also found the instructor role to be a strong contributing factor to students' motivation, with instructors also being cited as a key support system. There was a range of positive and negative experiences with instructors. However, those with positive experiences cited their instructors as being patient, dynamic, consistent, engaging, serious, helpful, caring, and supportive. Participants additionally reported 
curriculum and classroom dynamics as contributing to their motivation. This may include types of classroom activities, how the instructor facilitates activities, if they had opportunities to practice the language in class, and how engaging the activities were.

Tsang's (2012) research on student motivation/demotivation in Japanese language classrooms focused not on students' persistence to continue after completing the requirement, but rather on their motivation/demotivation and how it affected their learning behaviors and their motivation level in the class. Results provided new insight into student motivation, such as how participants cited their instructor as a key motivating factor. However, students indicated that how enthusiastic instructors were and how informative their feedback was to be leading motivators. Participants also reported a sense of progress to be a key motivator, which will be discussed more in the "Progress" section. Although the main focus of this study is not to research continued or sustained motivation, this is a valuable finding because it highlights the importance of instructor feedback, positive reinforcement, encouragement, and other ways instructors can help students to see their progress.

These findings show how the instructor is a strong contributing factor to students' motivation in a variety of ways. Instructors are so influential that their behavior and teaching approaches can be adjusted to actually increase students' intrinsic motivation, which has a longer-lasting effect than extrinsic motivation (Ryan et al, 2017). One way this can be done is to increase the students' autonomy.

\section{Autonomy}


Autonomy support from instructors is so influential that it may not only have immediate positive effects in the classroom but also have long-term effects on student well-being even after graduation, regardless of their academic or professional pursuits (Litalien, et al., 2012). Notably, students seem to be aware of the effect that autonomy has on their motivation, reporting that how class activities are facilitated, how engaging they are, and how much language practice the students had contributed to their motivation (Awad, 2017).

It is not only autonomy that students cite as having an effect on their motivation. Students recognize enthusiasm in instructors to be a leading motivator, along with giving informative feedback (Tsang, 2012). Feedback is another deciding component because of the instructor's ability to either highlight a student's errors or to highlight their progress, consequently, affecting their sense of competence. As previously mentioned, feeling competent in a subject is critical to fulfilling the psychological needs required for motivation (Ryan et al., 2017). Therefore, instructors can influence students' sense of competence by highlighting their progress.

\section{Progress}

Students report that an additional key factor in sustaining motivation to learn a foreign language is a sense of progress and improvement (Tsang, 2012; Allen, 2010). This again is logical because one of the psychological needs of SDT is competence (Ryan et al., 2017). In Tsang's study, students were encouraged when they felt they were progressing, whereas a lack of encouragement discouraged them from continuing their foreign language studies (Tsang, 2012). Students may also choose to continue 
based on the fact that they have already spent time and effort in the language and want to keep building on the progress they have made (Allen, 2010).

It is important to note that students not only want to feel that they are simply making progress, but additionally, are making progress through challenging material (Tsang, 2012). This shows that instructors should not give students unsubstantial, meaningless tasks with easily achievable goals for the sole intention of giving students a sense of accomplishment, but rather should challenge them with more difficult yet attainable goals, such that, when they achieve those goals, they feel that they are making real, substantial progress.

Students who are successful and make meaningful progress in a language are more likely to be motivated to continue (Ryan et al., 2017). These connections leave the question of what instructors can do during these language courses to have a positive impact on student confidence levels, which influences ability, success, and thus continuation of foreign language study. Luckily, this research shows the depth of influence instructors have and how much they affect a range of students' psychological needs. They are able to create an autonomous learning environment, which increases internal motivation and has long-term effects on well-being. They can give feedback that emphasizes the progress and competence of students and they are also able to support students. Thus, they have the ability to contribute to all three psychological needs for motivation according to SDT, namely, autonomy, competence, and relatedness. Next, I will discuss student confidence.

\section{Confidence in Ability to Learn the Subject}


When students are more confident in their abilities to learn a foreign language, they are more successful in their language learning process than students with low confidence, as Tunçel (2015) found to be the case with students learning Turkish. Moreover, Park, et al., (2004) found a positive correlation between self-perceived confidence and actual speaking ability in Korean students learning English. This correlational study measured aspects of anxiety and confidence in language acquisition ability and found that confident students are more likely to be more successful speakers than students with low confidence. Thus, these findings suggest that enhancing student confidence may also enhance language acquisition and proficiency. I will now review career as a motivational factor.

\section{Career}

A future career that implements a foreign language can be a motivating factor for students to persist in their language studies. Allen (2010) found that high school students cited career as a motivating factor to continue with their French studies at the college level. They cited the benefits such a degree might have on their careers after graduating college, for example, the addition of a French minor to an International Studies major. This shows that at least some high school students are already planning their future careers and the role foreign language may play. Moreover, Allen found that college students also cited the language's application to a career as a reason for studying it in college. These future plans to include a certain subject may be able to be influenced.

Certain teaching methods have been shown to increase interest in having a career in that subject. Xie et al., (2014), for example, found that integrating certain 
technologies in STEM high school courses increased student interest in having a career in a STEM field increased by $9 \%$ over the course of the program. Shin et al., (2017) found a similar motivation trend in STEM areas. Specifically, they found that students who are motivated to have a career in STEM are motivated to want to learn science, earn good grades, and have higher self-determination and self-efficacy.

Although these studies refer to STEM fields, they show how students are sometimes more motivated to learn a subject if it applies to their future careers. Moreover, they suggest that if students have good experiences in that subject make meaningful progress, that may also motivate them to persist in that field further and choose that field as their career path. This means either one could potentially come first; either students are first interested in a career field and so are motivated in those subjects or students make meaningful progress in a course and then choose their career based on that experience. This motivation to apply the language does not only pertain to a future career but may also appear in the form of wanting to apply the language to other real-world events (Allen, 2010).

\section{Desire to Apply Course Topic}

Allen (2010) found that students had a range of applications and use for a language that motivated them to learn it, such as being able to read literature in its original language or simply a desire to become fluent because of an interest in the target culture. This means students may be motivated to learn a foreign language to be able to apply their language abilities to a personal hobby or interest. In such cases, the language serves as a way to enhance an activity or subject in which they are already interested. 
Moreover, Allen (2010) found that many students wanted to apply their language abilities to real-life situations in the target culture. This was a means to practice and enhance their language abilities and help push themselves closer to fluency. They saw study abroad as an extremely beneficial step toward fluency because they could be immersed in the language and fully engaged in the culture. Whether it was for utilization in a future career, personal hobby or a situation abroad, students were generally motivated to study their foreign language for a specific purpose and application.

The factors discussed above pertained to continuing students and what motivated them. The following section reviews student attrition in foreign language studies and why students may decide not to continue.

\section{Non-continuing Students- Attrition in Foreign Language Studies}

Research on attrition in foreign language studies shares similarities with research on continuing foreign language studies in that motivation seems to be at the core of this decision-making. Research in this area is very limited, likely because reasons not to study a subject greatly vary (Curnow et al., 2007; Matsumoto, 2009; Ramage, 1990). Research focusing on discontinuing foreign language courses at the higher education level, including more recent research, is sparse (Matsumoto, 2009) However, research in other levels or areas of student attrition in a foreign language has found interesting results.

High school-level foreign language students who continue after their second year are more likely to have intrinsic motivation, such as wanting to learn the language simply for the sake of learning, in addition to having a higher interest in the culture 
and in increasing their knowledge and abilities to read, write, and speak the language (Ramage, 1990). Students who see a benefit to their future careers are also more likely to continue. Moreover, according to Ramage, continuing students felt positive about their language class and considered it to be both fun and challenging. Curnow et al. (2007), on the other hand, researched continuing and discontinuing secondary-level students in Australia and found that continuing students' main reason was more extrinsic, namely, their academic achievement in the subject. Continuing students also cited personal interest in the language as a reason for continuing; however, it was either secondary or in addition to their academic achievement.

At least two researcher teams have hypothesized that non-continuing students tend to cite extrinsic factors as reasons for taking languages and have less of a personal, intrinsic interest in being able to speak the language (Curnow et al., 2007; Ramage, 2009). Their main motivations are extrinsic, namely, to fulfill college requirements (Ramage, 2009). Once they achieve that, there are no deciding factors motivating them to continue. They tend to prioritize fulfilling college requirements more than continuing students, and intrinsic motivations, such as learning the language for the sake of knowledge, are much less present than they are in continuing students (Ramage, 2009). It is important to note that the non-continuing participants of the aforementioned studies did not plan on continuing when they first started. Therefore, it is logical that they would be motivated by extrinsic factors such as fulfilling college requirements.

It is additionally noteworthy that these studies focus on students at the secondary level and not in higher education, where students have more freedom in the 
subjects they study. There is very little research on student attrition at the higher education level and the studies conducted in this area have primarily been at Australian universities (Matsumoto, 2009). Although these universities are in a different country than the U.S., with different school systems, and therefore have different contributing factors that are possibly inapplicable to the American system, such studies can provide important information on phenomena to consider in the American higher education system.

Matsumoto (2009) researched university-level students in Australia to see if having a close cultural tie to the language influenced students to continue Japanese studies. He found that East-Asian students discontinued Japanese courses more than Western students. Therefore, having a closer tie to the language and culture does not necessarily mean students will be more motivated. Research on higher education students' motivation to continue or discontinue still remains very slim. This factor of cultural ties is crucial because students have much more freedom to choose their area of study in higher education, such as which courses they will enroll in for general education requirements or what their major or minor will be.

A few factors have been found to contribute to student attrition in foreign languages at the higher education level in Australia. Namely, starting the language after it is too late to complete a program in that language, having mixed levels of proficiency at the beginner level (which could lead to feelings of being disadvantaged by the true beginner student), and a category of students called "doubters," namely, those who are unsure about the benefits of learning the language and so are at greater risk for discontinuing (Martin et al, 2016). 
What the research has yet to consider is the change in motivation that leads to continuing foreign language studies. If a student never planned on continuing, it is logical when they do not. It is likewise logical that a student who planned on continuing does so. These studies do not take into consideration what might discourage a student from continuing who initially wanted to or what influenced a student to continue when they planned on stopping.

The language level of the participants in these studies is advanced, and so are not the majority of those enrolled in foreign language courses (Looney et al., 2018). The research conducted has given great insight into the motivation of intermediate or advanced students, such as college seniors majoring in a foreign language (Awad 2017; Tsang, 2012; Allen, 2010). However, if the majority of university students studying a foreign language are within the first two semesters and then do not continue, this research does not show what should be emphasized in the semesters when universities have the most students enrolled and who have not yet made the decision to continue. There has yet to be research conducted on the change students experience when they go against their initial intentions.

Furthermore, the research that has been conducted was with students far beyond the time period when they initially made the decision to continue. If participants are in advanced studies, it has been semesters or even years since they made their decision to persist. This is a crucial factor to consider, as motivational research in foreign languages has shown that timing is one of the most important factors when gaining information on motivational factors (Dörnyei, 2001). This means one can give more depth in reasoning for making a decision if it is a current 
issue or recent choice than if the decision was made years in the past and is no longer directly relevant.

In order to gain a more accurate understanding of students' decision to continue or discontinue foreign language studies, it would be beneficial to focus on students who decided not to continue when they initially planned to continue and also to focus on students in their first voluntary language course - when they have both just made their decision to continue or not. Research questions must examine variations in experiences the participants may have had throughout the course or semesters, thus addressing the ebb and flow of motivation levels, as Dörnyei (2001) states, including those present even within a single course.

This dissertation addresses these gaps in the research conducted thus far, with the participants all being students who changed their planned trajectory after taking introductory courses. This focus on the change of study addresses what may have happened in those beginner courses to influence them to either continue or discontinue. If students did not plan to continue or discontinue and their introductory courses influenced them to change these plans, that would be more promising in suggesting what can be done in those courses to influence them.

\section{Theoretical Framework}

Self-Determination Theory (SDT) is a theory of human behavior and personality development that examines biological, social, and cultural conditions that facilitate or hinder human capacities (Ryan et al., 2017). SDT is both a practical and critical theory. It is practical in that it examines how features of context affect motivation and satisfaction. It is critical in that it examines how social context 
supports or hinders human thriving (Ryan et al., 2017) There are three basic psychological needs that are a vital component in SDT, namely, autonomy, competence, and relatedness. Meeting these needs is required for psychological growth, integrity, and wellness. SDT and the three psychological needs within the model can be applied to any area; however, for the purpose of this study, I will focus on SDT's application to education.

According to Ryan et al. (2017), autonomy, the first of the three psychological factors discussed in SDT, is the need and ability to self-regulate one's experience and actions (Ryan et al., 2017). If students, for example, are autonomous, their actions are in-line with their authentic interests and values. Instructors who support student autonomy by creating an environment that lets students use their inner motives to guide their learning can actually increase students' intrinsic motivation (Ryan et al., 2017). Teachers who are not autonomy-supportive give extrinsic incentives and pressuring language in order to shape what students do, therefore, bypassing students' inner motives (Reeve et al., 2004). Such action decreases intrinsic motivation, which is crucial because intrinsic motivation has a longer-lasting effect than extrinsic motivation (Ryan et al., 2017). It is therefore advisable for teachers to nurture students' interests and inner-motives and not segue into a reward system of learning.

Competence, the second requirement within SDT, refers to the basic need to feel competence and mastery (Ryan et al., 2017). In an educational setting, this would mean that students need to feel like they are making progress or that they are good at an activity or in a subject. Competence diminishes when a task is too difficult or undermined by other factors, such as criticism or negative comparison (Ryan et al., 
2017). Therefore, it is advised that instructors make clear what students are doing correctly so they fully understand their progress. A focus on errors or on areas where they do not show mastery may diminish their sense of competence and this basic psychological need may not be met.

Relatedness is the third required need in SDT and refers to feelings of belonging and connection to others (Ryan et al., 2017). Students may fulfill this need by feeling that they are an important contributor and that their input is a vital part of the group or class's overall progress.

Satisfying all three of these psychological needs is essential for optimal motivation, whereas frustration with these needs is linked to lower motivation in addition to possible negative behaviors, such as aggression or greed to make up for the lack of this fulfillment (Ryan et al., 2017; Deci et al., 2008). Since meeting these three psychological needs is so dependent on experience, SDT is very applicable when researching student experiences and changes or developments in their motivation regarding foreign language learning.

Although SDT is my primary theory, I will also consider aspects of Bandura's Self-Efficacy Theory (SET). According to Bandura (1994), SET is defined as people's beliefs about their capabilities to perform at levels that influence aspects that affect their lives. He notes that self-efficacy beliefs determine how people feel, think, motivate themselves, and behave. These beliefs occur through cognitive, motivational, affective, and selection processes. One way Bandura (1994) posits that one can develop self-efficacy is by seeing peers achieve success, which serves as an example of how one can succeed. He explains that when students see other students similar to 
themselves succeed, they make the connection that they too may be better able to accomplish similar challenging tasks.

However, peer influence may also have a negative effect if one sees peers fail. The extent of the influence, whether positive or negative, is influenced by the perceived similarity between the students and the example students. The more similarity the students see between themselves and the example, the more likely they are to assume their outcome will be the same. SET may provide a clearer understanding of why students may continue or not continue, based on what they see in their peers. SET has not been specifically included in literature on why students continue or not continue; however, similar aspects such as support from peers, family, and instructors have emerged as contributing factors to students' continuing. This theory relates in some ways to SDT, wherein students need to feel like they are a part of a group and play a vital role (Ryan et al., 2017). Although there are differences in these concepts, they share the importance of social dynamics.

\section{Summary}

This chapter provided a review and discussion of research conducted that uses SDT as a theoretical framework. I discussed research conducted on students who continue on to advanced levels, including specific sections based on the results of this dissertation, such as support, autonomy, progress, confidence in ability to learn, career, and desire to apply the subject. Additionally, I discussed research on students who discontinue language studies, including the limitations in the applicable research on student attrition, or discontinuing students, in a foreign language. I then provided a description of the significance of this study, including a description of the gap in the 
literature and how this study helps fill that gap. I concluded the chapter with a discussion of the theoretical frameworks utilized in this study, namely, SDT and aspects of Bandura's (1994) SET. Next, I will discuss the research methods I utilized in this study. 


\section{CHAPTER 3}

\section{METHODOLOGY}

In this research, I used qualitative case study methodology because it is useful when the research goal is to examine how people and groups construct meaning (Patton, 2015). The research goal of this dissertation relates to students' meaning and experience leading to deciding to continue or discontinue studying a foreign language. In order to understand what motivated students to do this, and because the question focuses on "why", research needed to be conducted using a qualitative method that gathers data on students' experiences, the meaning they associate with those experiences, and their own description of those experiences (Yin, 2018). The specific qualitative approach I used is an embedded single-case study. My overarching research question was "Why do some students change their intended language study trajectory after completing introductory courses?"

Yin (2009) states that a case study is an empirical inquiry that investigates a contemporary phenomenon in-depth and in its real-life context. Patton (2015) defines case study design using a phenomenological perspective as distinct from a phenomenological study, but rather as looking at a shared experience or phenomenon, which is what I used. A case-study was the most appropriate and beneficial method to answer my research question. Case studies offer a means of investigating complex social units consisting of multiple variables to understand this real-life phenomenon (Merriam, 1998). 
In this case, the context was a beginner (first or second semester) foreign language course. The units of analysis were the students who changed their academic plans and decided to continue or discontinue these foreign language courses. The case is the act of the students changing their initial plans. An embedded single-case study was appropriate because there are multiple units of analysis within one context (Yin, 2009). Please see Appendix A for a design chart.

Interviews are necessary when the researcher cannot observe the behavior, feelings or how the participants interpret the world around them (Merriam, 1998). In order to collect data, I conducted interviews to gain an understanding of the students' experiences, feelings, and interpretations of what changed their minds and motivated them to continue or discontinue foreign language studies.

This case study allowed me to research this phenomenon in depth. I was able to discuss the participants' experience at length to gain a deep understanding of what pushed them in their first few semesters. A case study provided an opportunity to ask additional questions and clarify.

\section{Researcher Positionality}

Qualitative research is interpretive in nature and requires that the researcher is involved in a sustained and intensive experience with participants (Creswell \& et al., 2018). Therefore, the background of the researcher can assist the reader in determining how to interpret or apply this study. For this reason, it is important to know that I am an American who has learned German through elementary, secondary, and postsecondary education, as well as time abroad. I myself struggled considerably with foreign languages in middle school and it was not until my German class in high 
school that I realized I too could be multilingual, which I found very empowering. Following this experience, I not only continued with German studies but also enrolled in French classes in high school, Japanese during my undergraduate studies, and Spanish and French during graduate school. I, therefore, am a student who continued foreign language study past what was required and was once in a similar situation to the participants in the continuing group.

I have now taught German at a research university for over six years. One of the main reasons I love teaching is getting to see how students can start a language class with much trepidation but then gain more and more confidence in themselves and enthusiasm for the language and culture that they confidently hold conversations in the target language and travel independently in the target countries. Often after even just one or two semesters, I hear students state that they did not think they could learn a language but have realized they have, they enjoyed it, and want to develop their skills further.

The experiences I had as a language learner myself, along with working with undergraduate students and encouraging them to be successful language learners are what made me want to choose this research area. I would like to get at the heart of the experiences that led students to or away from the realization they could and will learn a language in higher education. Doing so will increase the ability of instructors and/or policymakers to make decisions that nurture such motivating experiences.

My role as an instructor influenced why I chose this topic to study but also influenced how I interpreted the data and since the participants know I teach a language, may have also influenced the dynamic of my interviews. To address these 
potential issues I took multiple steps, such as collecting multiple forms of data to cross-check the findings, such as between data from the initial survey, the three words provided at the beginning of the interview, and the discussion during the interview. I was able to cross-check what words students provided as motivational factors at the beginning of the interview and what they discussed during the interview. The emerging themes across participants were interpreted by the researcher and provided to the participants to ensure reliability. Limitations, biases, and methods implemented to reduce these will be discussed in further detail later.

\section{Research Setting}

Participants for this study were selected from a four-year research institution in the Northeast United States. This institution offers a wide range of language programs. At the time this study was conducted, there were no language requirements for undergraduates except for those with a business major who needed two semesters of any language. For those with other majors, a language course would fulfill general education requirements, as would a variety of courses unrelated to foreign languages.

\section{Participants}

This sampling included two groups of nine students, four non-continuing students and five continuing students, who volunteered to participate and who fit into the qualifying group of students. According to Patton (2015), a small homogeneous sample is most appropriate when in-depth information is needed about a particular group or subgroup. In order to gain enough information from the students on their experiences, a group of students with similar qualifications must participate.

Therefore, a form of purposeful sampling, namely, homogeneous sampling, was used. 
Qualification into the first group required that the students were currently in their first or second language course and were registering for the following course next semester and that they initially intended not to continue and to only complete their major or general education course requirement of one or two semesters of a foreign language, respectively. Qualification into the second group required that the students were currently in their first or second language course, were not registering for the following course next semester, and that they initially intended to continue on to further courses after completing their major or general education course requirement of one or two semesters of a foreign language.

The participants for this study had a range of majors, with three of the continuing students as business majors, Tucker, Tony, and Bill, and one noncontinuing student, Kara (Please note that throughout the remainder of this dissertation, pseudonyms will be used). Since this study focused on the plans of all participants for the following semester, which was not a requirement for business majors, all participants discussed whether or not they would take additional, nonrequired courses. The only difference being that some had been required to start a language in the first place, whereas it was voluntary for the others.

\section{Continuing Participants}

This group consists of students who started with the intention of dropping after one or two semesters. During their time in their course(s) they changed their mind and decided to continue. Please note that all names are pseudonyms. 
Table 1

Continuing participants

\begin{tabular}{ll}
\hline Name & Language \\
\hline Alicia & German \\
Tucker & Spanish \\
Alexander & German \\
Bill & German \\
El & Arabic \\
\hline
\end{tabular}

\section{Non-continuing Participants}

This group consists of students who initially intended on continuing past the beginner one or two-semester courses. During their time in their course(s) they changed their mind and decided not to continue.

Table 2

Non-continuing participants

\begin{tabular}{ll}
\hline Name & Language \\
\hline Brenden & Japanese \\
Tony & German \\
Evelina & French \\
Kara & Italian \\
\hline
\end{tabular}




\section{Participant Recruitment}

Motivational research in foreign languages has shown that when data is collected is a crucial factor when gaining information on motivational factors (Dörnyei, 2001). The participants are able to give more details when describing their decision if it is a current issue or recent choice, as opposed to if the decision was made years in the past and is no longer directly relevant. Therefore, the data would be most reliable if they are collected close to the time the participants made their decision to continue or discontinue. Thus, data collection was collected during the enrollment period for the following semester. Data collection took place in the participants' first or second semester of foreign language study and inquired about their plans for the following semester. Participants were allowed to be studying any foreign language, and no preference was given to those studying particular languages.

Participants were recruited through the institution's language department. Specifically, I contacted instructors of first and second-level courses via email and requested to visit their courses. I then attended, asked the instructor to leave the room, and personally introduced myself to students, described the study, and handed out consent forms for them to read and fill out if interested. Those who were interested filled out the consent form, chose a pseudonym, and provided me with their contact information, which I planned on using to set up in-person interviews; however, we soon switched to a virtual format.

These in-person class visits were conducted in mid-March of 2020 during the weeks before spring break. Approximately half of the participants were recruited inperson with in-person interviews planned for the week afterward. Following spring 
break the campus closed due to the COVID-19 pandemic and all courses were online. I, therefore, contacted those participants and set up the interview to be conducted virtually, using the format of their preference.

In order to increase the number of participants, I continued my recruitment measures by sending a description of the study to instructors to disseminate to their students. Additional students interested in participating then emailed me, we planned a time to meet virtually, and I provided them with the consent form. In this consent form they were able to write down their pseudonym for how they wanted to be referred to in the study.

\section{Data Collection}

Multiple sources of data were used because no single source of information can provide a comprehensive perspective and multiple data sources can be used to validate and cross-check findings (Patton, 1990). I used a total of four data collection sources (The participant interest form, the three words at the beginning of the interview, the semi-structured interviews, and a researcher journal used for memos). The first source was a brief participant interest form I disseminated while visiting classes. This consisted of questions that ensured their eligibility, specifically if they did in fact change their mind and study a language longer than intended or not as long as intended, when this decision was made, and what language they are studying. (Please see Appendix F for the participation interest form).

The second data source was planned as a written answer at the start of the interview; however, due to the change to a virtual format this question was spoken (Please see Appendix B for the interview protocol). This was a prompt asked at the 
beginning of the interview; "Please provide 3 words to describe what influenced your decision to continue/not continue with languages." The purpose of this prompt was to give a clear talking point at the beginning of the interview in which we discussed what they came up with, to allow the participants time to gather their thoughts before starting the interview, and to use these words to create a visual of these data in the final report.

The third and primary data source was collected using semi-structured interviews aimed at capturing the participants' description of their experience and their interpretation of that experience. In these interviews, the same set of questions was asked to each participant, with individualized follow-up questions aimed at capturing the participants' description and interpretation of their experiences. These interviews took place within weeks of the enrollment period when they decided to continue or discontinue on to a second or third semester. Conducting interviews near the time they made their decision is a crucial factor to consider, as motivational research in foreign languages has shown that timing is one of the most important factors when gaining information on motivational factors (Dörnyei, 2001). Specifically, if data is collected soon after the time the decision or action took place, the more accurate it will be.

Interviews were planned to be conducted in-person and on the campus where the participants' language courses take place; however, due to the COVID-19 pandemic they had to be moved to virtual. They were planned for up to 30-45 minutes and most were within that time frame. These interviews were audio-recorded and transcribed during the interview using the program Otter. The fourth data collection source, memos, were taken directly following the interviews to increase reliability. 
Participants then received a summary of the codes and themes from their interview and had the option of confirming or retracting any section. Participants had the option to choose a pseudonym in order to keep their information confidential. The name assignments, along with the transcripts and audio recordings are stored on a passwordprotected computer in a secure folder. Lastly, the fourth data source is a researcher journal I kept using memos to describe impressions from the interview and anything noteworthy from the interview or participant. These four data sources, the participant interest form, the three words at the beginning of the interview, the semi-structured interviews, and a researcher journal used for memos, gave a comprehensive view of the case and provided a means of cross-checking findings. Next, I will discuss the analysis of these data.

\section{Data Analysis}

Data were analyzed following the approach detailed by Creswell (2014): (a) Transcribing the data, (b) reading the data and writing general themes, ideas, and impressions, (c) coding data (d) describing the major themes or categories of the codes, (e) creating a representation of the data, (f) and the final step was interpreting the results. After reading and transcribing the data I created a coding frame based on the emergent themes from the interviews. At that time, I reread the transcriptions and coded them using Dedoose, a qualitative computer data analysis program. I then organized the codes along with key quotes that exemplified each code.

The interviews were transcribed immediately during the interviews using the program Otter. This program transcribed the interviews as we were speaking and also made an audio recording. After the interviews, I first wrote descriptions of my general 
impressions of the participant, focusing on what influenced their decision to change their language plans. I then listened to the interviews and read through the Otter transcription, correcting any errors or any parts left out of the transcription.

After reading through the interview transcriptions and listening to the recording, I added more information to my memos, including general themes, possible ideas for codes, and ideas on what the participant's turning point was. Miller et al., (2012) define motivational interviewing as listening for language regarding change or behavior that led to change. Since this study is based on finding reasons behind motivation, special note was taken to discussion that regarded the topic of change, in addition to any other emerging patterns or themes. These themes for non-continuing students were the desire to continue with a different format, course structure, including time, and progress. The themes for continuing students were confidence as a language learner and idolizing speaker, identity, peer and family support, family/family support, their instructor, their progress, their future career, and language application. The individual participants interpreted their own experience; however, the emerging themes across participants were interpreted by the researcher.

Using these themes, I made a list of potential codes, which developed more as I reread each interview. After rereading all of them I could then decide what the recurring themes were that could be codes and what themes were more specific to just one person or themes I thought were recurring but were in fact only minimally mentioned.

I then added the transcriptions to the coding program Dedoose. This process further solidified what my codes would be. I read through each interview and selected 
quotes that represented codes or the recurring themes. This process narrowed down my coding frame. For example, while selecting quotes I realized that some of the themes I chose as codes were not specific to motivation but were more descriptive of the participation requirements. One instance of this occurring was a code called "intentions" which was a set of quotes of students describing what their plans were. Since this was inherent in the recruitment requirements, I deleted this.

Additionally, more codes were added, such as "idolizing speaker." This one consisted of descriptions of participants' dreams of having someone else's abilities in the language. "Time" was another code that was added during this process after realizing that many of the non-continuing students felt they were unable to continue with the language due to the time commitment. Under "Intentions" a subcategory called "Desire to continue with a different format" was added during this time period due to the realization that most of the non-continuing students still wanted to learn the language and specified that they would like to use a different format, such as home programs or a slower-paced course. Despite initially thinking this was only the case for a couple of students, I realized this was the case with most non-continuing students and I believe this is one of my key findings. Please see Chapter 4 for more details.

After the coding process was complete, I wrote out descriptions of the results and compared them to the theories I used, such as Self-Determination Theory and aspects of Bandura's Self-Efficacy Theory, in addition to ones that related to findings I did not predict, such as Dörnyei's "Ideal L2 Self." Please see Chapter 4 for more details. 


\section{Ethical Considerations}

As Merriam (1998) details, the researcher is the primary instrument for data collection and analysis in qualitative research, therefore researcher bias must be taken into consideration. Clarification and a clear description of past experiences and researcher positionality are provided in this dissertation, which makes the researcher's position clear to the reader.

In order to overcome the potential challenge of the researcher being the primary instrument for data collection, I needed to take certain steps to ensure construct validity, such as method triangulation, or cross-checking, and member checking. Triangulation of data means comparing and cross-checking the consistency of information derived by different means (Patton, 2015). For example, I was able to compare data from the initial survey, the three words provided at the beginning of the interview, and the discussion during the interview. One step to ensure validity is to collect multiple forms of data to cross-check the findings (Rowley, 2002). I was able to cross-check what students provided as motivational factors at the beginning of the interview and what they discussed during the interview.

Member checking is a procedure that involves referring the data back to the participants to check the accuracy of the interpretation and results (Fraenkel, et al., 2012). I provided a summary of emerging themes to the participants, which helped to ensure their statements were being applied and interpreted accurately (Creswell, 2014). This gave them the opportunity to confirm or deny the accuracy of the emerging themes. No participant disagreed with the interpretations. 


\section{Chapter Summary}

The purpose of this chapter was to describe the process I used to collect, analyze, and interpret the data. I provided a description of why my methods were required. Specifically, why a qualitative case study was the most beneficial approach to gain the required data and results. A description of my history as a language student and language instructor provides positionality for the reader to understand my background and how it may influence the study.

I described the details of how I carried out the study. Specifically, the setting for the study and from where I recruited the students. I provided descriptions of the recruitment process and how the start of the COVID-19 pandemic affected that process. There are brief descriptions of the participants, which groups they fall into, and what their language is.

I then provided descriptions of how the data was collected, analyzed, which methods were used to increase reliability, and how the data was coded. This includes some examples of the shifting coding frame and how I created the codes and major themes by transcribing and rereading the interviews.

Limitations along with steps taken to ensure reliability and assuage these limitations are provided at the end of this chapter. This is provided to assure the reader that steps were taken to ensure the accuracy and reliability of the data. 


\section{CHAPTER 4}

\section{FINDINGS}

The purpose of this study was to explore the experiences of beginner language students to gain insight into what occurs during their courses that influences and motivates them to continue or discontinue their language courses. The main research question was: Why do students change their intended language study trajectory after completing introductory courses?

To do this, I conducted semi-structured interviews with a total of nine participants. Five of them belonged to the category of students who initially did not intend to continue but after taking one or two semesters decided to continue. The remaining four belonged to the category of students who initially wanted to continue but after taking one or two semesters decided not to. I then transcribed the data, read the data and wrote general themes, coded the data, and created a list of prominent themes (Creswell, 2014). I will first discuss emergent themes from the group of noncontinuing students and then themes from the continuing students.

There were four prominent themes among non-continuing students. The first being that they wanted to continue learning the language in a format other than in a college course. The second was their issues with how the course was structured, such as homework, assignments. The third theme, which is related to course structure, was the issue of how much time the course required. This often led to the fourth theme of a lack of meaningful progress in learning the language. 
There were five prominent themes in the group of continuing students. The first was their new-found confidence as a language learner and realizing they really could learn the language. This often was connected to idolizing a speaker of the language and after seeing their example, realizing that they could do it too. The second theme was wanting to use the language in a future career. This motivation to apply a language spanned not only to a career but also other situations in which they wanted to apply the language. This desire to apply the language to situations such as specific conversations or situations in the target culture was the third theme. The fourth theme, support, came in the form of peer, instructor or family support. The fifth theme was having a sense of meaningful progress. The continuing students felt they had made meaningful progress in the language and wanted to continue on this trajectory.

\section{Table 3}

Themes Among Non-Continuing Students

Theme Definition

Desire to continue with a different format This theme refers to when students want to continue learning the language but not in classes, but rather on their own, such as with computer-based language programs.

Issues with course structure

Time
This refers to issues related to how the course is structured, such as number of assignments, type of assignments or time commitment. This theme relates to course structure and 
refers to the time commitment a course requires to succeed.

Progress This theme refers to the lack of a sense of meaningful progress in the language.

\section{Table 4}

Themes Among Continuing Students

\begin{tabular}{|c|c|}
\hline Theme & Definition \\
\hline Confidence and Idolizing Speaker & $\begin{array}{l}\text { This refers to the new-found sense of } \\
\text { confidence to learn the language. This } \\
\text { often connected to idolizing another } \\
\text { speaker and wanting to do the same. }\end{array}$ \\
\hline Identity & $\begin{array}{l}\text { This refers to who the students do not } \\
\text { want to be anymore, namely, a } \\
\text { monolingual English speaker }\end{array}$ \\
\hline Career & $\begin{array}{l}\text { This refers to wanting to learn a language } \\
\text { to apply to a future career. }\end{array}$ \\
\hline Language application & $\begin{array}{l}\text { This may be a specific situation in which } \\
\text { the students want to use the language, } \\
\text { such as study abroad. }\end{array}$ \\
\hline Support & $\begin{array}{l}\text { This is feeling supported by others, such } \\
\text { as family, friends or instructors. }\end{array}$ \\
\hline Progress & This refers to the sense of making \\
\hline
\end{tabular}


meaningful progress in the language.

\section{Summary of Each Group}

\section{Non-continuing}

Non-continuing students started out with and retained confidence in their ability to learn a language. They still planned on learning the language in another format. Course structure forced them to discontinue but their desire to learn it remained. They have a desire to learn the language, sometimes for career, personal interest...etc. but the structures of the university course influence them to discontinue.

\section{Continuing}

Continuing students started out unsure if they could learn a language and had low confidence. Their progress, new-found sense of confidence in their ability, and admiration for other speakers showed them they could learn the language and be successful. Improvement in job opportunities was a bonus. They did not seem to have any issues with course structure or time commitment.

\section{Findings in Non-Continuing Student Group}

\section{Desire to Continue with Different Format}

The non-continuing students were people who started their language studies fully intending to continue long-term. This means something that happened in their class or because of their class that deterred them from continuing. One of the most noteworthy themes that emerged from the non-continuing group was that the majority still wanted to learn the language and still, despite no longer wanting to be a student in the language program. 
They spoke of still thinking they could learn the language and some even had specific plans to do so on their own. Brenden, for example, was motivated by a personal interest in gaming and by his career plans to use Japanese for computer programming. He was so motivated to learn Japanese that he had plans to study it on his own and still had plans to use Japanese in his future career. Despite these motivators, he was deterred by the course structure; "that's why even if I don't decide to continue in college, I'm definitely gonna try and find a different way to learn Japanese maybe even more at my own pace.” The Japanese course Brenden took required a significant amount of time dedicated to learning vocabulary, which was simply too much for him. He desired proficiency in Japanese but thought it had to be done on his own, with his own resources, and at his own speed.

Tony also spoke of wanting to continue with German but at his own pace using his own resources.

So, right now. It's hard enough already, so why would I want to pile on so but after college and if I am willing enough, I have time and money to go to a place that I can learn the language or go through and do the online Rosetta Stone, for German or Spanish or French then I would absolutely."

He had decided that if he wanted to learn a language, he could do it on his own, without the pressure from a course to learn a certain amount by a certain time. He found his schedule difficult even without the language so thought he could learn German in a way that suited him better and did not make life more challenging.

Kara had seen herself make progress in the Chinese program and still wanted to learn Italian. She had even made travel plans to Italy; however, she was forced to 
cancel the trip as the severe outbreak of COVID-19 took over Italy; "I am always gonna want to learn Italian just maybe not right now with this program." Despite her plans to discontinue formal language studies, she still planned on learning Italian and had a strong desire to visit Italy to use her language skills. It was the course structure that was the problem, not her desire to learn Italian.

These non-continuing students were motivated to learn the language, were confident that they had the ability to do so and yet were dissuaded from continuing in their programs. These were some of the main traits that the continuing students had gained in their time in their foreign language courses that influenced them to continue. Therefore, they were just as interested in learning the language as the continuing students but factors outside of the students' control dissuaded them from continuing. This should be very disconcerting to those in higher education looking to encourage students to study foreign languages and to continue their language programs. When asked about what discouraged these students from continuing, issues related to course structure were one of the most prominent themes. Next, I present findings on the issues non-continuing students had with course structure, including time requirements and a lack of making meaningful progress.

\section{Course Structure}

Course structure was one of the prominent themes among non-continuing students. This refers to barriers within how the course was designed, such as the time it requires, the number of assignments or type of assignments. The main theme in course structure relates to time, which I will discuss now. 
Time. Time was a prominent issue when discussing course structure. These courses required more time than the students were able to devote to them. These findings are new to the body of literature on student attrition in foreign language studies. Previous studies have focused on all discontinuing students and therefore resulted in participants giving reasons for discontinuing such as not being interested in learning the language, not having career goals that apply the language, and only taking the language to get course requirements and therefore discontinuing as soon as they can (Curnow et al., 2007; Matsumoto, 2009; Ramage, 2009). Because this dissertation is the first study to consider why students may discontinue when they initially planned on continuing, the findings that students who were initially planning on continuing often did so because of time restraints and issues with course structure are novel.

When interviewing these students, there was a sense of being forced to quit their language studies. They were still interested in learning the language and believed they could. However, because the language was not their major and required a larger time commitment than they could give, they did not make the progress they wanted and felt they could not continue.

One student, Brenden, particularly sounded sad that he could not continue because he really had a love for Japanese. He spoke in-depth about how discouraged he was that he was not making the progress he wanted because of the course structure. Specifically, the high volume of vocabulary words he was required to learn for every class. Not having the time to keep up, he concluded, can only result in him needing to stop his language studies. When asked what would have made him continue with Japanese he responded, 
I had more time to learn everything or I guess. Or, if I had more time to learn everything.

Because the way it is right now. The two biggest solutions for my biggest problem is either having more time in class to absorb things and go at a bit slower pace or spend more time out of class memorizing everything. But as of right now. I can't really do either of those things. So if I had more time would be the best.

But it's sort of that thing where like, for, it's not my major. And if I have to like to pull all-nighters to pass the class. It's not really feeling worth it because, you know, it would take... 'cause like if I fail if I, you know, don't pull all-nighters at night sort of will, you know, not do well in the class and that will hurt my GPA, but if I don't pull those all-nighters and I'll be taking time away from focusing on my major, which is my primary goal. So it's sort of like a turning into like almost a necessity that I should stop.

This theme resonated from my conversations with Tony as well. He discussed not being able to take the time required to keep up with the course. Like Brenden, his major courses needed to take preference.

I would have continued with German if I invested more time into it.

If I was able to, if I had more time to be able to go through this concepts longer and go through and get through every single word, and get it done. Then I do believe that I would be able to get it. 
Also, I think I would have continued (language) if I wasn't doing a double major. If I hadn't decided that I wanted to double major.

Because, I would have been like, wow, I like doing this, I know I have the course schedule that can permit this. And so, because I am already doing the double major it just comes down to I can't let something affect my double major, I can't affect something like my major, with a minor, the only thing that could affect my major is one of the majors.

So that was, that was my mindset prioritizing the major.

Tony would have continued with German if he had the time available to dedicate to it and if he made meaningful progress in learning the language. Since he felt he needed to dedicate that time to his major, he felt he needed to stop taking German. Brenden and Tony both thought their major studies needed to take priority over their language studies. Although they both still had interest in learning the language, it ultimately was too much of a time commitment to continue and took too much time away from their major courses. Brenden took issue with the course structure that required an unreasonable time commitment. Tony, on the other hand, took no issue with the course setup and in fact admired how the course was structured but had issues being able to comply. He recognized the effective format of the course, but because of his time restraints he was unable to participate as he should.

I just have been doing (homework program), but I've been rushing it. And that's not the way that (the faculty) have designed it to be and that's not the way that I, I know that I'm not supposed to and I know that that's not the way I'm 
supposed to be doing it but that's just... been having trouble when it comes to "done everything! Oh yeah, I have German."

Tony liked the format of the course or saw the effectiveness of it, even though it did not fit with his schedule. He finished all of his other work and saw German as an add-on that was taking extra time and, therefore, did not see progress. Since the students could not devote enough time to their programs, the courses were simply an ineffective means of learning the language. This means they did not make enough progress to make it worthwhile, which was a key issue and reason for them discontinuing. Next, I will discuss the theme of progress in more detail.

\section{Progress}

The common thread of all of the participants' issues with the course setup is that they made it so the students could not make the progress they wanted to. The students were all motivated and knew they were capable of learning a language and who started their language studies with the intent of continuing. They expected to make progress and be successful language learners. These issues with course structure all led to them not making enough progress and therefore, deciding to discontinue their language program.

Kara specifically mentioned this connection.

I want to continue with Italian if the class structure was a bit different. And I saw more progress.

If I went to Italy, I would have been like Ciao and that's it. I don't think I could hold a conversation, beyond like my name is (Kara). You know what I mean? 
So that's why I was like, I don't know if I want to continue learning Italian in this way because I'm not learning as quickly as I am with Chinese.

Kara felt she was putting too much time into studying a language to not see many results. It simply was not worth the small amount of progress she was making. According to SDT, progress, or "competence" in a subject is critical to fulfilling psychological needs required for motivation. Competence diminishes when a task is too difficult or undermined by other factors, such as criticism or negative comparison (Ryan et al., 2017). The factors these students experienced, such as how Evelina felt negatively compared to other students or Brenden who was assigned the too difficult task of learning an exorbitant amount of vocabulary each day, did indeed have diminished competence. This made them think the courses were not worthwhile, and they therefore discontinued.

Kara took issue with the rigor of her program and therefore the pace of her progress. She was a particularly interesting participant because she was simultaneously taking Chinese and Italian. She saw herself making great strides in Chinese and so by comparison her Italian courses did not seem to be worthwhile. Her participation in this study is based on her experiences in her language that she is not continuing. In these courses, she felt that the instructor did not hold high standards for her students. "She was like, just get the homework and get the quizzes done and get the writings done on time. That's like all that matters." Her instructor emphasized the assignments but not the actual use of the language and progress in the language. Kara discussed how she was discouraged that her courses did not require students to use the target language in class. 
So I expected like coming to college, there would be a lot more like less of a crutch in English like the teacher would be a lot more strict and like not using English just using Italian, even if it was like, basic Italian words. I thought that would be a lot more like that. But then when I got here, I guess because it's such a low level, it was like she spoke Italian but she spoke a lot of English as like a crutch. So I kind of felt myself doing the same thing I did in high school, which was like, not really care. And just like sit in the class, and just do the work but not actually like retain anything.

Since the instructor did not value the amount of target use in class, Kara did not either and found herself disinterested. This aligns with the "competence" aspect of SDT. Kara was able to complete the tasks and do well in the class, but because the tasks were too easy, she did not feel competent in Italian and saw no progress. Her Chinese courses, conversely, were demanding and more difficult, but because she saw progress her efforts were rewarded. Her efforts in her Italian course, while successful, were not rewarded with progress and competence in the language.

Similar to Kara, Brenden and Evelina also did not see the progress they expected due to course structure. Like Kara, the effort the course demanded was misguided or was not at the appropriate level and, therefore, they saw no meaningful progress. Brenden, for example, was motivated and was interested in learning Japanese, but had to put too much effort into learning vocabulary, which did not result in meaningful progress to him. 
I'm learning the stuff, but I'm only learning to pass the test. I'm not learning to memorize which is my biggest issue was one of my biggest issues back in high school. And what I was kind of hoping would not be the same as in college but it sort of is ending up being like, where we're learning all these words just to pass the test. And then once that's done, we just forget them all, which is not what I was hoping for. I was hoping this would be, you know, learning words and keeping and retaining them. And you know, I could probably put a bit more effort into memorizing everything but again with this not being my major, I don't have enough time for that.

Brenden is motivated to learn Japanese and wants to see real progress. However, his course makes him simply learn for a test and then forget the material. Evelina similarly was challenged too much or was challenged in a manner that made her unable to progress. Her main reason for not continuing was a lack of progress and issues with the course setup. She felt she was unable to be successful in the course because it required her to teach the concepts to herself and use class time to reinforce the material.

One thing that like made it difficult and made me really not want to continue. I know I like kind of touched upon it but like the way like the classroom, like is so like, you have to like teach yourself as like, I already don't know the language like how am I going to know what I'm doing is right, or if it's wrong, and like I could like be doing something wrong for so long that I remember it. Then when it comes to actually doing it. Everything that I thought was correct 
was wrong. Like in class is just like a reinforcement like I wish it wasn't that way.

Evelina was worried about "fossilization". This is when an error becomes a habit and is difficult to correct (Chen et al., 2013). This made her hesitant to learn the material on her own. She would have felt more comfortable using class time to learn concepts directly from the instructor, as opposed to using it to practice the language. Although this would likely be more comfortable, it likely will not result in as much progress (von Glasersfeld, 1989).

It seems she would have been more comfortable with a behaviorist teaching approach of a teacher as a sender of information and students as the receivers; however, this simply is not an effective learning method (von Glasersfeld, 1989). In the foreign language classroom, this approach may take the form of the instructor explaining grammar and the students taking notes or the instructor reciting phrases and the students repeating them. Although it may be more uncomfortable and make students leave their comfort zones, a constructivist approach that includes participation that will then generate learning will result in higher success (von Glasersfeld, 1989).

Fosnot (2005) defines constructivism as describing knowledge not as truths to be transmitted or discovered, but as emergent, developmental, nonobjective, viable constructed explanations by humans engaged in meaning-making in cultural and social communities of discourse. This approach rejects the notion that instructors can transfer knowledge to students, but instead that students take ownership of the idea and become empowered (Fosnot, 2005). 
Based on Evelina's description, she had a constructivist method used in her class, but it was still not effective in motivating her to continue and helping her make progress. There may be a few reasons as to why this is. Firstly, she did not feel her instructor was supportive of her, moreover, she felt isolated in class and did not feel like a meaningful member of a group. This means that many aspects needed for motivation, such as support and relatedness, were not met. Additionally, the course may not have been at the appropriate level or may have challenged her too much. Class time was used to practice material that she was not prepared to practice. Like Brenden, the course challenged her too much or in a way that made her feel left behind.

Kara, Brenden, and Evelina's situations differ in the manner in which they needed to be challenged; however, they had a common issue of not progressing in a manner that was meaningful to them due to course structure. Whether it was too strong of a focus on vocabulary, not enough target language use or too much reliance on selfstudy, the tasks given to them were not aligned with the manner in which they wanted or needed to be challenged. They, therefore, were lacking the psychological need for a sense of competence and saw no purpose in continuing.

\section{Findings in Continuing Student Group}

Themes among continuing students can be summarized by them gaining a sense of confidence in their ability to learn a language. The motivators that tipped the

scale to make them want to continue tended to be intrinsic, such as a new-found sense of ability and progress in the language. Extrinsic factors such as improving their job 
chances were also mentioned as strong motivators but did not seem to be the factors that convinced them to continue and were mentioned more as an additional benefit.

\section{Confidence as a Language Learner and Idolizing Speaker}

Students gaining confidence and an understanding that they are capable of learning the language proved to be a main motivational factor among continuing students. This aligns with the literature on confidence and progress. As discussed in chapter two, students are more successful in learning a language when they are confident in their abilities to do so (Tunçel, 2015). In fact, there is a correlation between confidence in students and actual speaking ability (Park et al., 2004).

It is particularly noteworthy that continuing students did not start with this confidence but gained it during their courses because the non-continuing students started with and retained this confidence. The non-continuing students started their courses with this same sense of ability to learn the language and confidence that they could, but outside factors such as course structure were enough to dissuade them from doing so. The continuing students did not have this sense of ability when starting their language program but gaining it was enough to convince them to continue. The continuing students did not, however, cite course structure as a factor, be it positive or negative. This leaves the possibility open that if they had had an issue with the course, their desire and confidence to learn a language may not have sufficed, as was the case with non-continuing students.

An anecdote that students repeatedly told was situations in which they admired someone else's abilities in the language. Aligning with Bandura's Self-Efficacy Theory, students saw peers or someone similar to themselves successfully using the 
target language, which motivated them to want to do the same. Whether they were continuing in their language program or not, students who were still interested in learning the language shared stories of admiration.

El, for example, talked about meeting native Arabic speakers her age and being inspired by seeing people her age who could speak the language fluently. ...all of a sudden, they have like little side conversations together in Arabic I just thought that was really cool. ... So, I just was really, I thought it was really cool to see people my age who I'm friends with just casually having a conversation in a foreign language.

El admired her peers' ability to switch so casually to Arabic and it made her want to do the same. Some students told stories of not just admiring others' abilities in the language but admiring the speaker they could be. The students desire to possess certain language abilities because it fits their idea of who they want to be as a second language speaker. When they desire it for themselves it follows Dörnyei's (2005) notion of the "Ideal L2 Self." This is an aspect of intrinsic motivation in which someone is motivated to increase their language abilities because they believe they should possess these abilities for their own sake of self-improvement.

These continuing participants are intrinsically motivated to be a multilingual speaker and, therefore, have an "Ideal L2 Self". They saw where they could be and the speaker they could be, which motivated them to continue. Students described what it would be like to see native speakers and be able to communicate with them by saying this like "that's wicked cool," "I am just in awe, I would like to be like that." Since 
they only reference their own desire to be multilingual and the admiration they have for that ability, they are striving to be their ideal, multilingual selves.

El, the student who admired her native speaker friends, wanted to be multilingual to be able to help people like her non-American friends by learning their language. She did not want to have to be the person to need accommodations but rather wanted to be the one who could reach out to them by using her multilingual skills. Tucker similarly described wanting to be, as he described, the one to "bridge that language barrier." Tony, despite not continuing, described planning to learn multiple languages on his own because of his admiration for "when people belt out different multiple languages." They desire this multilingual ability for themselves, and therefore are striving to become their "Ideal L2 Self."

\section{Identity}

These students who are motivated by the speaker they could be also mentioned who they do not want to be anymore, namely, a monolingual English speaker. They seemed to be grappling a bit with their identity as American or monolingual English speakers and of wanting to expand out or push away from that. El, for example, wanted to grow past her identity as a monolingual English speaker and develop into a multilingual speaker. "There's people like me who just know one language, and some people are okay with that but I want to be able to communicate with other people in different languages besides English.” She saw herself moving away from her old monolingual self. She was accepting of people not wanting to change that about their identity; however, she was attracted to that development. 
Additionally, Alicia discussed not wanting to fit the "dumb American" stereotype, and knowing another language helped push her away from that. "I feel like, not dumb, but I feel like it's a responsibility to learn another language because not everyone speaks English and it's ignorant to think that." She then told a story about seeing some Americans that fit exactly what she does not want to be. However, they did provide a good contrast to herself, which helped her see the progress she made.

There were these two guys in front of me. They were obviously American you could tell by multiple factors. One they were only speaking in English and a very loud, loud like voices and tones, they're wearing like they're all very heavy set. The one guy that really killed me was wearing like a McDonald's tshirt so they were just not dressed up well and I could tell that the poor cashier person was like completely done with it like she says oh you're stupid American scribbling under her breath, she was just completely done. I was behind them I was wearing my nice clothes because we had a company visit. So, when I was able to actually like we made through most of the transaction through German it just sort of made me like, Oh, I think I can do this made me so excited I was really happy. The only part that tripped me up was when she asked, "Would you like a plastic bag?" and I just said I had to reveal myself as the American saying sorry No, and she looked pleased that someone else was bothering to learn the language, so I think that really was a big part.

This experience showed a stark contrast to Alicia. She saw a stereotype of her culture and wanted to show that she was not a part of that. Being able to have a 
successful conversation motivated her because it was confirmation that she was, indeed, multilingual and possibly able to not be recognized as a non-native speaker.

In addition to Dörnyei's “Ideal L2 Self” he also describes the "Ought-to L2 Self." This "ought-to" self refers to traits someone believes they ought to possess to avoid a negative outcome or perception from others (Dörnyei, 2005). This does not necessarily mean they desire this for themselves. If Alicia were to avoid being a stereotype to avoid someone else's disdain for it, it would follow the "Ought-to L2 Self." Since she wanted to be successful in her German conversation for herself, she is invoking the "Ideal L2 Self," although she additionally seems motivated by the “Ought-to L2 Self” because she feels the judgment from the store worker.

\section{Peer and Family Support}

According to SDT, students are more motivated when they feel supported in their pursuits and feel they are important members of a group (Ryan et al., 2017). Relatedness is the third psychological need in SDT and refers to feelings of belonging and connection to others (Ryan et al., 2017). Students may fulfill this need by feeling that they are an important contributor and that their input is a vital part of the group or class's overall progress. These participants were clearly motivated in part because of the support they felt from those they care about.

Participants in the continuing group often cited support from friends and

family as a factor that helped motivate them to pursue their language studies further. Peers not only helped provide an example of what the students could be but they also helped motivate each other to take the class in the first place or to continue.

Alexander, Bill, and Tucker all started their language studies, at least in part, 
due to a peer's suggestion and Tucker and Tony chose their specific language because of family members. Bill, for example, had a brother who had a good experience so suggested German to him, Alexander also started his language studies because a friend had suggested it because he had had a good experience. Tucker had support from both family and friends. His grandparents spoke Italian and so he wanted to be able to share that connection with them. He also credited friends' support and his good experiences in class as his decision to take and continue his language studies. "It was definitely not an idea until sophomore year and then after having that experience and then talking with friends about it, that's $100 \%$ why I chose to do it." These examples of peer and familial support are important reminders of how beneficial it can be to progress toward a goal with others and satisfy this psychological requirement of "relatedness".

\section{Instructor}

Although the non-continuing students mentioned their instructors on occasion, they did not seem to be the determining factor in their decision not to continue. The continuing students, however, often specifically cited instructor support as a motivating factor for them. El was particularly inspired by her professor and saw him as proof that she could learn Arabic too.

I really didn't know what to expect as far as who my professor would be, if it was a native speaker or someone who has been practicing the language for a long time. You know I didn't expect some tall skinny white man to walk into the room and be like, I'm your Arabic professor. And so that was a little bit... It kind of more like a wake-up call that anyone can really learn any language that they want. 
It was not only motivating to her to see that an American could also speak and be a professor of other languages, but also by the fact that he could relate with her and her struggles learning Arabic. Brenden, who decided not to continue, felt disconnected from his professor and thought she may not understand his struggles. El, on the other hand, decided to continue and felt her professor understood what she was going through in her language learning process.

My Arabic professor, he understands you know what parts can be difficult, how it can be difficult, like not feeling motivated at times, but you know he's kind of proof that if we work hard enough, we can get to where he's at. El saw her Arabic professor as coming from a similar situation being both American English speakers. She saw that he had gone through the struggle to learn Arabic and was proof she could get past it. El and Tucker discussed how their instructors were the force that convinced them they would indeed learn a foreign language. Tucker spoke highly of his instructor and described how she gave him confidence that he could not only learn Italian but any language. He had not had a positive experience with foreign languages before her course, but afterward, he knew he could learn any language that could help him.

I would not have continued if it weren't for Professor (Name), I had no doubt in my mind...I remember every class she'd come in with a big smile and she'd immediately engage us and start to start talking Italian and get us to everybody in the room and start talking.

Her ability to engage the class and get Tucker and his classmates to speak and use Italian showed him it was possible for him to be engaged in a language and that he 
could really use it. Many of the continuing students spoke of the support their instructors and the faculty gave them. Alicia spoke of regularly visiting some faculty members when she was feeling insecure about her abilities to succeed in her program. “They definitely helped me with my decision like every time I'm struggling, I do pop in their offices and I'm like, Hey, give me a pep talk, please. And they always do." It was motivating for her to have this support structure that allowed her to visit faculty and right away be motivated by them and their support. Alexander also was motivated to continue after a talk with his professor in which he showed him the progress he had made and encouraged him to pursue German further.

I mean, it's kind of fun learning a new language, because then I can, like, I was making stupid jokes with a friend like we're trying to speak German to each other, which was fun. But I wasn't really considering it until I think I had my conference with Professor (Name) and he's like alright let's just go over your grade, and he's like, Hey, you have an A in the class, I am like "What?" And he's like, "you should consider... strongly consider continuing it." And I thought about it.

This was a noteworthy story because it showed how instructor support motivated him, but also how confirmation of his progress and competence in German was motivating to him. His instructor made it clear that he was indeed succeeding and making progress. Moreover, Tucker's instructor saying he should continue showed him that the professor was on his side, he wanted him to be a part of the program, and he valued his progress. 


\section{Progress}

Competence, the second requirement within SDT, refers to the basic need to feel competence and mastery (Ryan et al., 2017). In an educational setting, this would mean that students need to feel like they are making progress or that they are good at an activity or in a subject. Based on the interviews, making progress and successfully using the language gave students a boost of confidence, showed them they really could learn another language, and motivated them to continue. Similar to how a lack of progress made the students decide to quit their language studies, making progress also made the students want to continue. This supports the claim of SDT that students must be competent and make meaningful progress in a given area if they will be motivated to continue (Ryan et al., 2017).

Many of the students had had disappointing experiences with a foreign language in the past and this new-found success gave them confidence for the first time in their foreign language skills. Brenden, Alicia, El, Alexander, and Tucker all mentioned their distaste for their foreign language in K-12. They discussed how being forced to take a language course had made them not dislike foreign language courses, with some even questioning their ability to learn a language in college. Disliking their foreign language courses because they felt forced aligns with the autonomy aspect of SDT, which states that in order to be motivated, one must be able to self-regulate one's experience and actions (Ryan et al., 2017). They were unable to self-regulate their experience in K-12, which led them to dislike foreign languages.

With this as a backdrop, the students saw themselves making progress in a foreign language for the first time. Alicia told a story of being able to successfully use 
German to buy some things and how it bolstered her faith in her language abilities; "So, when I was able to actually like we made through most of the transaction through German it just sort of made me like, Oh, I think I can do this made me so excited I was really happy." She saw how she was in fact capable of successfully applying German to a real-life situation.

Bill also saw progress in a foreign language for the first time in college. He had had a difficult time with his Spanish courses in high school, but in college, he saw himself doing well in his German course. This was encouraging progress in a foreign language that he was experiencing for the first time.

I can compare it like I feel like if I sit down with a Spanish paragraph I'd be sitting there for hours not understand anything. Give me like 30 minutes with a German like any writing and I feel like I could probably make something out of it, like absolutely I can probably understand, at least the basis of whatever the writing is but it's a little bit easier language, to me at least.

He felt the progress he was making, which was not the case when he tried to learn a language in high school. Something about German came easier to him than Spanish had.

...this was the first time another language kind of clicked for me and German has. I feel like I haven't, like, fully understood it yet but I feel like I'm gonna, it's easier for me to kind of teach to myself, I thought.

Bill felt German "clicked" with him and it was the first time he realized that he could be successful learning a language. Many had been discouraged by bad experiences in K-12 studies so were motivated when they found a sense of 
accomplishment and ability. This realization that they could be successful in their language connects to many other themes, such as progress/success, support from instructors and/or peers, language application. Alicia, Tucker, Alexander, and Bill all found motivation in their new accomplishments and progress.

\section{Career}

It is noteworthy that every single continuing student and even some noncontinuing students mentioned their future career as a factor for them wanting to learn the language. Most discussed taking language courses not only as a way to make their resume more appealing to employers but also discussed the specific ways being multilingual would enrich their future careers.

Career application is an important aspect of motivation because it gives them a purpose to learn the language. Brenden saw the use of his language for the games/programming industry, El saw a benefit for her future career working in law and with refugees, Alicia and Alexander in Engineering, Tucker in business, Tony in business/banking, and Bill in supply chain management. Rousseau (1979) states that when someone needs a skill because he or she sees the purpose, he or she will increase their participation and enhance their knowledge on the subject. He gives an example by describing a fictional student, Emile, who has no interest and little skill in reading until reading a note, which has a purpose for him. When students will have their own chosen application for the language, such as to a future career, their motivation is increased, and they are more likely to want to learn it (Ramage, 1990).

Many of the participants talked about choosing their language as a resume booster or as something that would increase their chances of finding meaningful 
employment after graduation. What all of these students share is that career benefit is a reason they took the language in the first place; however, they did not mention it as a reason for changing their minds and deciding to continue. Considering this, along with the fact that career was often a reason why non-continuing students took their language, it's clear that career is an important factor that influences students to choose the language in the first place, but it was not the tipping point that convinced them to continue. Moreover, as previously discussed, it was also not enough to convince the non-continuing students to stay in their language programs. This means it may be a motivator of initial enrollments in a specific language program, but not of retention in a language program.

\section{Language Application}

The fantasy of one day using their newly acquired language in situations abroad occasionally arose in the conversations with the participants; however, it was only a determining factor for one student. Gardner and Lambert's (1972) model for motivation in foreign languages shows that students are more motivated when they have a positive attitude toward the target community and want to communicate with that community. This certainly was the case with the continuing students who wanted to engage with the target culture and be able to successfully communicate with them. Alicia, Alexander, El, and Kara all talked about looking forward to one day putting their language knowledge to use in the target culture. Alexander was particularly motivated by that opportunity and said it was one of his main reasons for deciding to continue. 
I like the idea of going abroad, especially because I'm from Rhode Island and I'm going in-state, so I am not really getting that far from home. The appeal of going abroad is very strong. And like it's an opportunity that I might not have again in the future. And one of the things on my bucket list is actually snowboarding on the Alps. So all of that kinda just sounds awesome.

Alexander realized that study abroad was an opportune time to get to travel and was a chance to leave his home state.

Similar to how students' career influenced their decision of which language they would study but not their decision to continue, study abroad or the idea of using their language one day seemed to mainly come as an added benefit but not as the turning point and convinces them to continue or not continue.

\section{Summary of Findings}

Students who initially planned on continuing past one or two semesters and then decided not to mostly did so because their language programs were not conducive to their learning. They were generally students who were intrinsically motivated, interested in the target culture, had career or personal applications for the language, were confident in their abilities to learn the language, and most noteworthy, still planned on learning the language in another format. The format or structure of the courses hindered their progress, so they did not see the value of them and saw no reason to continue. There was generally a sense of disappointment that they did not find what they were looking for in the program.

Students who initially planned on only taking one or two semesters and then decided to continue generally did so because they gained new confidence in their 
ability to learn a language. This was due to a range of aspects, such as the progress they had seen, the support from their peers and instructors, wanting to see themselves as multilingual people, the desire to apply the language in the target culture, and to improve their career options.

\section{Summary of Participants}

\section{Alicia (continuing)}

Alicia is studying German and is planning on continuing. She was unsure at first and was nervous about starting a language. She was considering dropping it for a time. She compared herself to other students in class who understood the material faster, which made her think she was not making enough progress quickly enough. Despite being successful in her high school French courses and college German courses, she thought she had issues or particularly difficulty learning languages. This may tie to her experience with speech therapy at a young age.

During a study trip to Germany Alicia gained new confidence and identity as a language learner. After having successful conversations in Germany, she realized that she really could learn the language. Peers also influenced her on the study trip because she saw students ahead of her who had learned German and gotten quite good at it. Moreover, Alicia wants to promote the idea of the multilingual American and thinks it is her duty to be multilingual. She doesn't want to be seen as a stereotypical, monolingual American.

\section{Tucker (continuing)}

Tucker had his first university language in Italian and took it just to fulfill requirements. Because of this class he realized that he really could learn a language 
and had support from peers and his professor and family. His career aspirations influenced him to switch to Spanish. Italian made him realize that he could learn a language and since Spanish would be beneficial in his business career, he wanted to take his new-found confidence over to Spanish. He had fun in class, produced Italian, and saw himself make great progress.

\section{Alexander (continuing)}

The change for Alexander to continue happened when he realized the progress he had made in his German class. This decision was solidified by the fact that his father got a job at a local institution, which allowed for a tuition waiver and the opportunity to study abroad.

He had had a bad experience with Spanish in K-12 classes and dropped them as soon as he could. He thought that he may have a better experience at the university level and that they would be better and more effective.

His class was structured in a way that helped him learn and was effective. The students studied the material before class and used class time to produce the language. His professor was very supportive and approachable. He helped him realize how well he was doing with German and gave the personal touch of encouraging him to continue.

The words he chose to describe what motivated him to continue were money, grades, and opportunity.

\section{Bill (continuing)}

Bill's decision to change his mind and continue with German was primarily due to the success he saw himself making. He could see himself becoming fluent, 
whereas previously with high school Spanish he never felt that and did not think he could ever be fluent in Spanish. Something about German clicked for him. Autonomy was a contributing factor. He mentioned that Spanish was forced on him so was not motivating, whereas German was his choice so helped keep his interest. A second motivator was that he wanted to study in Germany and do an internship there. He saw the benefit for his business career in speaking German and having experience there.

The words he chose to describe his decision to continue were ease, interest, and understanding.

\section{El (continuing)}

El started Arabic and regretted it within the first week. Then she started to really connect with her professor and classmates. She found it motivating for her to see that her professor had also learned Arabic as a non-native speaker so she knew it could be done.

Peers were a big motivator. She got to know native speakers in her class who could speak but would struggle to write just as much as she would. She spoke of the camaraderie of her class, since there were only about 15 people, they got to know each other well. She really enjoyed spending time with those people her own age and hearing them speak Arabic. They motivated her to want to be able to do that too.

Another motivator for El was that learning Arabic was a challenge. She struggled with Spanish and also Mandarin in K-12 and once got to Arabic and still struggled, she came to accept that learning a language would be a challenge, but she could in fact do it. She realized that she could do it and nothing worthwhile is easy. 
Moreover, El plans on pursuing a career in law to work with refugees. She believes having a background in Arabic will benefit her in this aspect as well. The words she chose to describe her decision to continue with Arabic were peers, professors, and a challenge.

\section{Brenden (non-continuing)}

Brenden's main issue that led him to not continue with Japanese was workload and the time it took. His voice was filled with concern and a bit of sadness and frustration that the class was not working out because he really did want to learn Japanese.

He talked about needing more time to learn and retain vocab, although he is doing well with grammar. A slower, more digestible course pace would be good for him. He seemed to really want to learn Japanese and have intrinsic motivation from a personal interest in games, wanting to be able to play games only in Japanese, and also motivation from his major of computer science and wanting to have Japanese skills to use in the gaming industry in Japan.

Class expectations were too high for him to keep up, despite wanting to continue. It seems a different format with lower expectations or in a class with little bits of recycled vocab at a time would benefit him more. He seemed to be frustrated that he did not retain as much of the vocab as he would have liked. The experience that made him want to stop is seeing vocab he thought he learned and realizing he had not retained it and that he was just learning for a test and then forgetting it. This quote summarizes his reasons: 
Since Japanese is not your major, it is too risky to continue since it may hurt your GPA. Also, at this pace retention of vocab is difficult so you are not seeing the course being conducive to your success in Japanese.

The three words Brenden chose to describe why he decided not to continue were "intense workload."

\section{Tony (non-continuing)}

Tony decided not to continue with German largely due to the time commitment it required. He felt he needed to prioritize his major and German was taking too much time for him. He in no way blamed the course set-up, professor, environment...etc., as many other non-continuing participants did. Simply that external factors like prioritizing his major and wanting time for extracurricular activities like sailing took all of his time.

Tony was initially interested in taking French because it is the sailing language. His parents did not want him to and so he switched to German. He did not say why his parents did not like French, just that they did not want him studying that in college.

Tony has a strong sense of who he is as a learner. He talked about how he learned in elementary school, such as knowing that once he invests in something, he knows he has to do it. He also stated that he knows he will not do well on the first quiz of any course "I don't do well with the quizzes or anything that's the same way I've always been for math, and for physics in high school and all these other classes."

He also seemed to have the identity of someone who had a harder time with languages. He talked about how with English and later with Spanish he was put into 
the lower levels in school. Despite this, he thinks he can learn languages and would still like to learn German but only with certain methods and in his own time.

The three words Tony chose to describe why he decided not to continue were time, procrastination, and workload.

\section{Kara (non-continuing)}

Kara was an interesting participant because she was simultaneously studying Chinese and Italian. She initially planned on continuing in Italian, loved the language, and planned on traveling there at the start of the COVID-19 pandemic so had to cancel travel plans.

She did not feel like she was making meaningful progress, did not think class time was used wisely, specifically she thought there was too much reliance on English and not enough Italian use or encouragement to use Italian in class. Because of this lack of progress, she decided to discontinue.

Moreover, her decision was also influenced by the Chinese courses she was taking in which she was making significant progress very quickly. This comparison made her realize that her Italian course was not worthwhile. She wants to still learn Italian one day and believes she can. However, because she did not feel like she was making progress she thought she would drop it to focus on Chinese, where she was making great progress.

The words she chose to describe her decision to discontinue Italian were class structure and how it was taught. 


\section{Evelina (non-continuing)}

Evelina had been scarred by her experience with French. She said would never study it again. However, she maybe would study Spanish, since it is similar to Creole, which she speaks. This was different from the other non-continuing students who said they were still interested in the language, knew they could learn it if they wanted to, and planned on learning it in a different format.

She initially planned on minoring in French. Initially, she had confidence in her abilities to succeed throughout the first semester. However, she became overwhelmed in the second semester, did not make the progress she wanted to, was lost, struggling, and had low confidence. Moreover, she felt judged by the other students in class who seemed to not be struggling like she was.

The course structure was problematic for her. She did not like how she had to teach herself and then use class time as reinforcement. This is noteworthy because this is what Tony did like about his German course. She mentioned she did not like learning herself because she worried about fossilization and that she was learning and reinforcing the language incorrectly. Her tone throughout the interview was a bit scared and worried. It seems her experience with her course must have really scarred her.

Evelina is different from the other non-continuing students who still want to learn their language because she does not want to ever study French again. However, what made her want to stop is her course set-up, how she feels judged in class, her lack of progress, and how much she has struggled this semester. 
The three words she used to describe her decision not to continue were difficulty, lost, and struggling.

\section{Chapter Summary}

In this chapter, I review the themes that emerged in my interviews with participants. This consisted of a section on what influenced non-continuing students to decide to stop their language studies. These themes included how they still wanted to learn the language by using a different format than traditional college courses, their issues with course structure, their issues with the time commitment these courses require, and their lack of progress. I then outline the themes among students who changed their plans and decided to continue. These consist of their new-found identity with the language, confidence in their ability, and how they idolize those who can speak it. Additional motivational factors were their desire to use the language in their future careers, their desire to apply the language to other situations such as while traveling, the support they felt from family, friends, and instructors, and the meaningful progress they had made during their time enrolled in these courses.

In addition to outlining the results based on themes I also describe each student and the factors that most influenced them to continue or discontinue. These contain the same information as the previous sections organized by theme. This summary organized per student is included for the reader to gain a better understanding of who these people are as a whole and to provide a clear picture of which combinations of motivation factors each student may have. Additionally, this section includes each persons' selection of which words best describe their decision to continue or discontinue. This chapter ends with two images, created from the words each student 
chose. The size or position of the words do not reflect how frequently they were stated. 
What are three words that best describe what made you change your mind and continue with (language)?

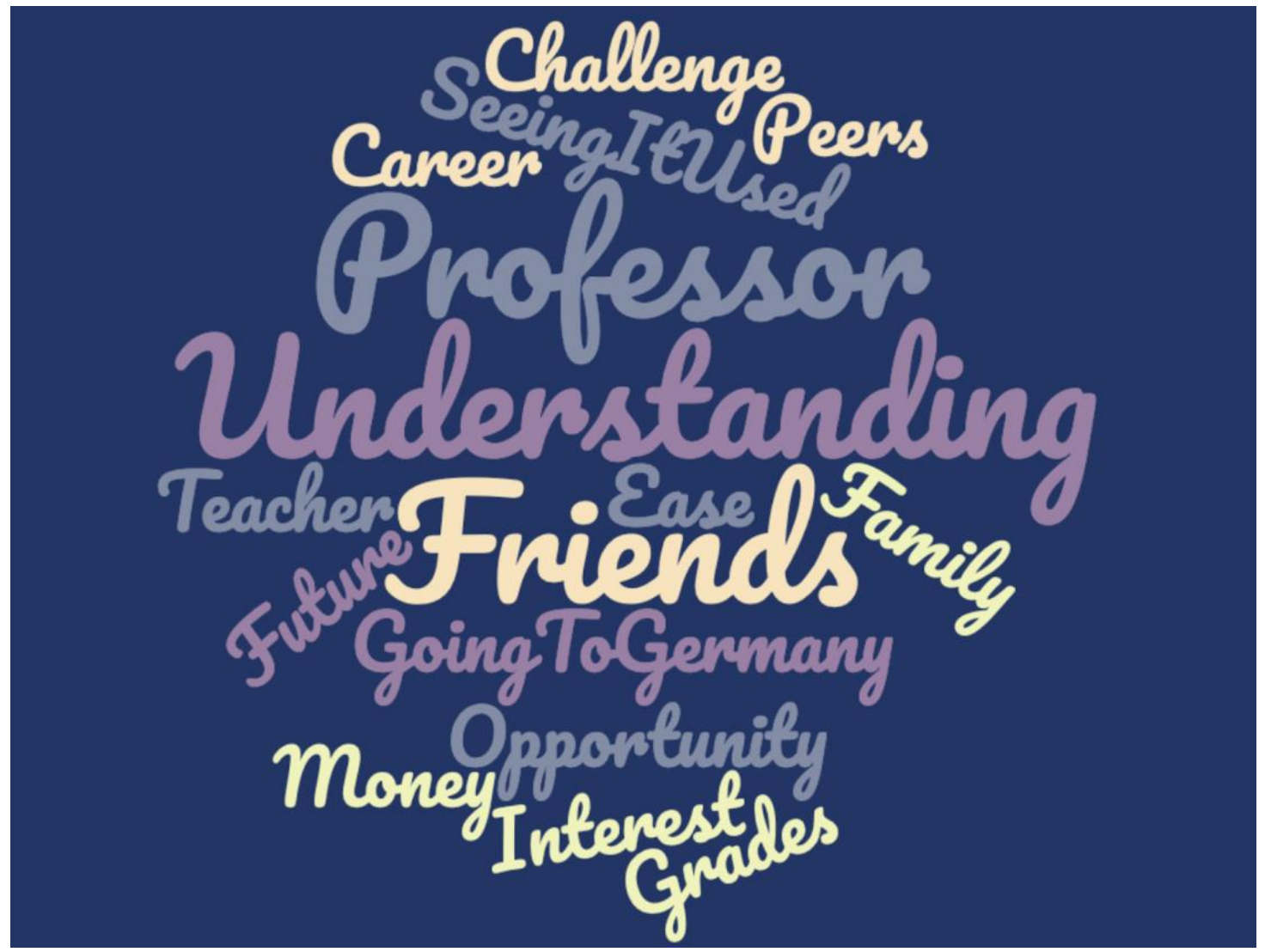


What are three words that best describe what made you change your mind and not continue with (language)?

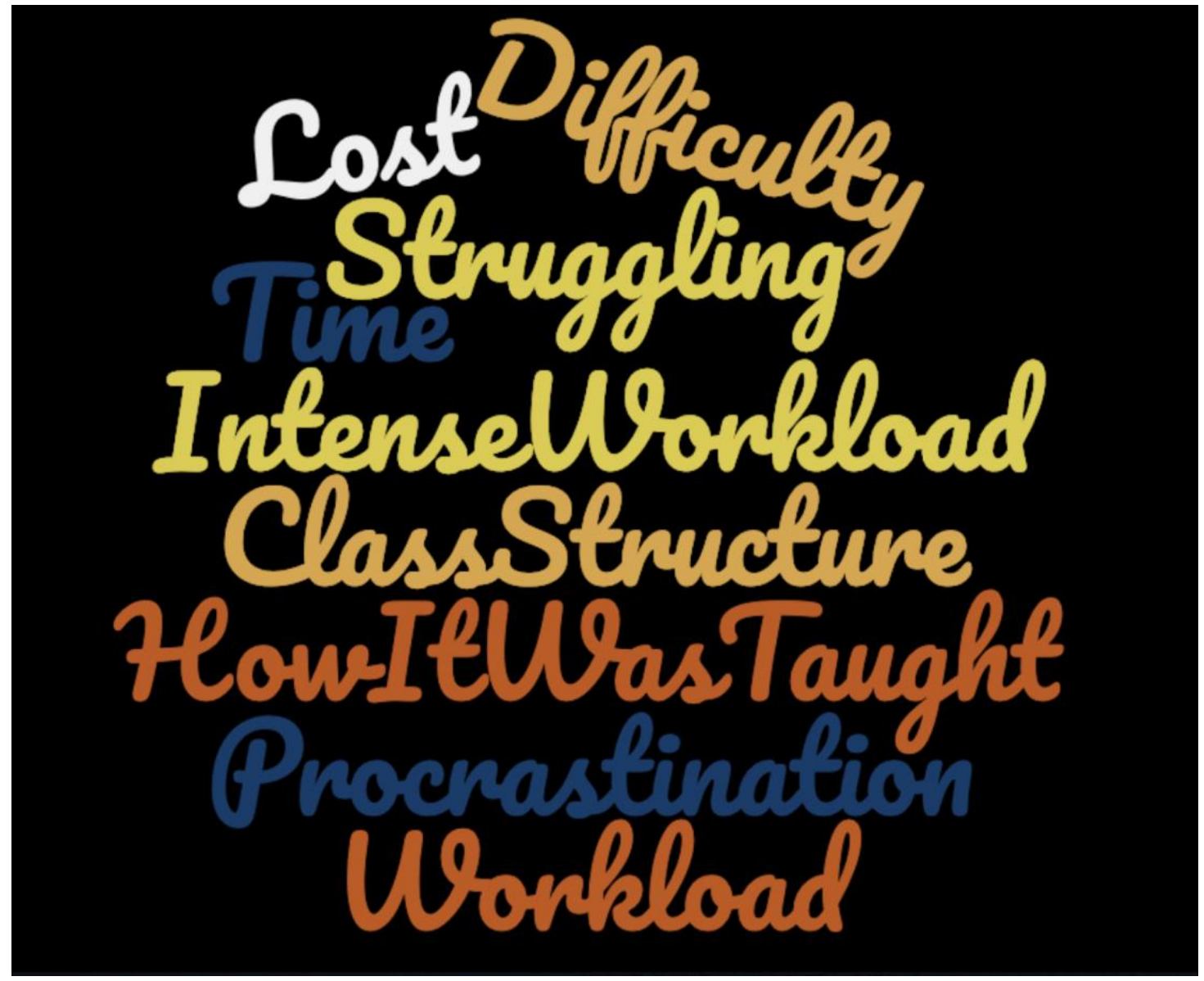




\section{CHAPTER 5}

\section{DISCUSSION}

The purpose of my study was to explore the experiences of beginner language students to gain insight into what occurs during their courses that influences and motivates them to continue or discontinue their language courses. My research question was: Why do students change their intended language study trajectory after completing introductory courses?

The answers to this research question are complex and will be divided into themes from both the non-continuing students and continuing students. I will then provide recommendations to administrators and instructors on what can be done to increase student motivation to continue their foreign language studies and will conclude the chapter with ideas for future research.

\section{Interpretation of the Findings}

This section includes my interpretations of the emergent themes from the findings. I will start with the issue of time, which led many students to discontinue. I will then discuss progress or the lack of progress, which led students to decide on continuing or discontinuing. The next subsection is on confidence in ability to learn the language, which nearly all participants had. This is followed by support from peers and family, a future career, and the desire to apply the language. 


\section{Time}

Many of the non-continuing students explained reasons pertaining to course structure as why they felt they could not continue. They discussed issues such as the amount of homework or studying required and aspects within the classroom. Most of the various reasons given shared the common theme of time. The fact that so many students gave aspects related to time as the reason they could not continue shows how the time requirements for a course need to be enough to make progress in the course but also must be achievable by the students. They need to devote enough time so that they make progress without that time being so much that it is unachievable and unsustainable. The issue of time being a determining factor in continuing or discontinuing language studies is a new finding. Previous studies on why students discontinue have focused on all discontinuing students, as opposed to only ones who changed their plans (Curnow et al., 2007; Matsumoto, 2009; Ramage, 2009). Results ranged from students not being interested, not wanting a future career that involves the language or only taking it to fulfill a requirement. Next, I will discuss the progress or lack of meaningful progress students felt.

\section{Progress}

A specific aspect that non-continuing students credited for not continuing was that the course was not conducive to their progress in the language. Students who did not feel like they were making meaningful progress did not want to continue. In this non-continuing group, many of the obstacles to the students' progress are controlled by the instructor. For example, Kara's instructor not using enough of the target language, Brenden's instructor assigning too much vocabulary too quickly for the 
students to retain, and Evelina not receiving enough support out of the classroom to teach herself the material. These are all issues that the instructors can improve, based on the needs of their course and their students. Although some descriptions of their experiences may sound discouraging to faculty, what is promising is that instructors can influence their students in multiple ways that encourage and motivate them to continue their language students.

This finding relates to other studies that found that a sense of progress and improvement was a contributor to motivation. (Tsang, 2012; Allen, 2010). Tsang (2012) found that students felt encouraged when they saw that they were making progress and when they did not see this progress they were discouraged from continuing. Moreover, this connects to one of the psychological needs of SDT, which is competence. When students feel they are competent in an area, they are more motivated to continue putting effort into it (Ryan et al., 2017).

As discussed in Chapter Two, this progress needs to be in challenging and meaningful areas, it cannot simply be progress in any menial task (Tsang, 2012). As we saw with Kara, she was successful in her Italian course. However, it was not challenging to her, therefore the progress she saw was not seen as a motivating accomplishment. Additionally, Brenden would study a large amount of vocabulary, pass a test, and then forget the material. This competence or progress was also not motivating because it was not meaningful. Next, I will discuss the students' confidence that led them to believe they could learn the language, whether or not they were continuing. 


\section{Confidence}

It was surprising to see that most non-continuing students still identified with the language and were still confident in their ability to learn it. What was interesting about these students is that they were still confident in their ability to learn the language and they mostly described aspects pertaining to course structure as reasons why they are discontinuing.

This shows me that for them to continue there would have to be changes at the course or instructional level, not changes to their attitude, desire to learn the language to their confidence. It would be easy to assume the reasoning behind discontinuing lies within these aspects of the students; however, it seems to be aspects within the instructor's or department's control, and therefore, can be improved with some changes. Please see the "Implications" sections for ideas.

Confidence correlates to motivation and success in language learning (Tunçel, 2015; Park et al., 2004). However, because the courses did not help them progress, these students did not seek this success from courses, but rather from other means of learning a language, such as with computer programs. They retained their confidence in their ability; however, they sought out other means of learning that may be more conducive to their learning.

What was most noteworthy about the continuing students was that one aspect that influenced them to do so was that they gained a sense of confidence in their ability to learn the language while enrolled in these courses. Students who started language courses with the intention of quitting changed their minds in part because they realized that they were indeed able to learn a language. It was this same 
confidence that the non-continuing students often started with and retained even after discontinuing. However, the continuing students first gained a new sense of confidence in their ability to learn a language because they had been making meaningful progress in a course that was structured in a manner that was conducive to their learning.

These findings align with research from Tunçel (2015) and Park et al., (2004) who found that students are more successful in their language learning process when they are more confident in their abilities to learn a foreign language. In particular, the continuing students did not previously have this confidence and gained it during their language course. This new-found sense of ability would indeed be encouraging to them. These findings suggest that enhancing student confidence may also enhance language acquisition and proficiency. Please see the "Implications" section for ideas. I will now discuss the support students felt or did not feel from their peers and family.

\section{Peers and Family - Support}

The support that continuing students cited as a motivational factor aligns with SDT, which, as previously noted, states that students are more motivated when they feel supported in their pursuits and feel they are important members of a group (Ryan et al., 2017). Relatedness is the third psychological need in SDT and refers to feelings of belonging and connection to others (Ryan et al., 2017). Students may fulfill this need by feeling that they are an important contributor and that their input is a vital part of the group or class's overall progress. Participants in the continuing group often cited support from friends and family as a factor that helped motivate them to pursue 
their language studies further. These participants were clearly motivated in part because of the

support they felt from those they care about. Interestingly, Tony was not supported by his parents in his desire to study French and he did indeed end up studying German instead. Other participants in the non-continuing group did not cite a lack of support as a factor in their decision not to continue. However, Tony's experience in his lack of support and the continuing participants' experience of support from family and friends as motivating is consistent with the "relatedness" psychological need of SDT and other research supporting the notion that students are more motivated when they feel supported in their efforts (Awad, 2017; Ryan et al., 2017). Next, I will discuss students' career goals and how languages may apply to them.

\section{Career}

Every continuing student and even some non-continuing students mentioned their future career as a factor for them wanting to learn the language. They discussed the benefits of knowing another language and how it would enhance their future careers. Moreover, it gave them a purpose to learn the language and gave them a place to apply it. This aligns with Ramage's (1990) research that found that students have increased motivation when they have their own chosen application for the language. This also relates to the autonomy aspect of SDT because the students have their own chosen area to apply and use their language skills. When students have choices and autonomy, they are more motivated (Ryan et al., 2017).

It is noteworthy that the students chose the specific language based on their career; however, there was no mention of career being the reason for taking a language 
in the first place. Moreover, they did not mention it as a reason for deciding to continue, showing that it was not the tipping point that convinced them to continue but was more of an additional benefit. Allen (2010) found that college students also cited the language's application to a career as a reason for studying it in college, further showing this link to a future career may be a beneficial retention method. I will now discuss the students' desire to apply the language to real-life situations.

\section{Desire to Apply Course Topic}

Four of the participants discussed how they looked forward to being able to apply their language in the target culture. Gardner and Lambert's (1972) model for motivation in foreign language shows that students are more motivated when they have a positive attitude toward the target community and want to communicate with that community. Moreover, Allen (2010) found that students had a range of applications and uses for a language that motivated them to learn it. These could be personal hobbies, but the participants also mentioned that study abroad was a necessary step in the language learning process. They wanted to apply their language abilities to real-life situations in the target culture. These findings also held true for Alicia, El, Kara, and particularly Alexander, who all had a positive attitude toward the culture and talked about how excited they were to be able to use their language skills abroad and interact with the native speakers. Alexander stated that it was one of the predominant reasons for continuing with German. These students were all motivated to study their foreign language for a specific purpose and application.

All of these findings lead to a number of tactics instructors and administrators can use to help motivate their students to continue. They range from simple statements 
to students to ways of marketing language programs to incoming students. I will now discuss implications for administrators and instructors.

\section{Implications}

This section provides recommendations to administrators and instructors on ways to help motivate students to continue in their foreign language studies. The interviews shed light on a number of areas that could easily be improved. Most discontinuing students would have liked to continue learning the language, were disappointed that the program was not beneficial to them, and clearly discussed why. The continuing students were also very articulate about what was motivating to them and what aspects of the course and instructor were beneficial.

When discussing how to get students to continue their language studies, administrators and instructors may think it is completely based on the students' personal decisions or may consider marketing methods. It is clear that why students continue or discontinue is often based on aspects within the instructors' control. This should be encouraging news because, although it may take work and much thought on the part of the instructor, the results show the instructor can strongly influence the trajectory of the students' language studies. How institutions and instructors treat and interact with their students has the potential to encourage or discourage them. I strongly recommend to always reflect on the dynamic between institution, instructor, and student and understand that the students are not acting alone, but often in reaction to their institution and instructors.

This is not an exhaustive list of ways to implement the findings of this study. Please take the results and apply them in ways that work for you or your institution. I 
will begin with recommendations to administrators, followed by recommendations to instructors.

\section{Recommendations to Administrators}

Motivated students who are capable and interested in continuing should be able to do so in some format. Since time commitment was often what stopped otherwise interested and motivated students from continuing, this is an area that should be addressed. One recommendation to solve this issue would be low credit, low stakes language courses that provide some exposure to the students so they still have some outlet to practice the language, without requiring more of a time commitment than they can handle. Such courses may take the form of a one or two-credit course or possibly a three-credit course divided into two semesters instead of all in one. The possible downside to this format would be that the students may not make progress as quickly as they would in a more intensive course. However, if the alternative is them discontinuing their language studies completely to instead learn from an online program, offering such courses might be worthwhile. This also leaves the possibility open that they may enroll in a class again in the future if they were able to stay involved in the department and keep up with the language, albeit for fewer credits.

The issue of credits affects more than just the time commitment of students. It is also the way institutions measure student progress in a language since students fulfill language or general education requirements based on credit hours. However, using this system ignores whether or not they truly gained proficiency in the language. If students are only enrolling in a couple of courses, it is to be expected that they graduate without language or cultural proficiency or the ability to apply for jobs 
requiring multilingual and multicultural employees, opportunities that have been increasing exponentially (New American Economy, 2017). Whether they truly make progress is irrelevant because they only need to earn a certain number of credits to either fulfill general education requirements, major/minor requirements or to simply show they took foreign language courses. One solution to help emphasize the actual progress they make in language ability is to replace semester, credit-hour requirements with proficiency-based requirements. Specifically, requiring a certain level of mastery of the language, as opposed to the number of courses completed.

Using semesters as a measurement bypasses what is really important. If graduates, for instance, need to participate in a meeting with Spanish-speakers, it is irrelevant how many courses they enrolled in, but rather what proficiency level he or she gained during that time. If language requirements were to shift away from a semester model and towards a proficiency model, it would advantage heritage speakers by giving them credit for their abilities. It would also encourage nonheritage students to not skim through the required courses but would instead require them to delve into the language and culture and apply it to their field of study in meaningful and applicable ways.

This approach is a drastic shift from the common credit system that has been used. Proficiency-based requirements may not be able to completely replace credit requirements; however, certain major programs can have the requirement of a proficiency level as opposed to a number of credit hours. For example, majors that would normally require a certain number of courses could instead require a certain proficiency level. 
Many universities use the phrase "proficiency" but still link it to a number of courses taken (Neuman, 2017). Proficiency can instead be, and optimally is, defined as what students can do with the language (ACTFL, 2012). A proficiency level that a university requires could be one within the ACTFL proficiency range, which has four categories of Novice, Intermediate, Advanced, and Superior, which three subcategories of Low, Mid, and High in each of these (except Superior). Depending on the institution or major, for example, a university may choose to replace the 2semester requirement with a Novice High or Intermediate Low requirement. This model would shift the priority to a certain proficiency level, then provide students with examples of how this may be obtained. These may include being a heritage speaker, participating in study-abroad immersion, taking as many courses as a student needs to reach that proficiency goal or some other creative approach. I will now discuss ways to increase students' connection to the target language and culture since participants were motivated by seeing peers speak the language and by having opportunities to apply the language.

Providing opportunities for local and international students to connect could be beneficial to both groups of students. Belkin, et al., (2016) discuss how international students frequently live with other students from their home country and have difficulty integrating with American students. A survey of over 450 international students in the South and Northeast showed that nearly $40 \%$ of international students had no close American friends (Gareis, 2012).

International students and American language students can connect in multiple ways. In addition to ways instructors can include them as classroom assistants, they 
could also be hired to lead conversation groups outside of class or in campus cultural activities, such as German or Japanese movie nights. These give students simple ways to interact with each other and practice speaking with each other. Universities may also provide incentives for international students, such as stipends for leading conversation groups or teaching one-credit conversation courses.

When American students live in foreign language housing, they make more gains in the language than students who only have exposure in the classroom (Martinsen, et al., 2011) Therefore, it is recommended to provide such housing options. When cultural housing is available, if international students are interested, they may be provided housing with American students studying their language. This would increase cross-cultural exposure, provide an opportunity for international students to get more involved on campus, and to increase the American students' opportunities to use the language, which is a benefit to both groups. Next, I will discuss how to address the motivational aspect of a future career that involves languages.

Since career arose frequently in interviews as a reason for choosing their language but not for continuing, it may be a beneficial factor for recruiting students into a certain language program. When advertising programs or even designing them in the first place, linking certain majors or certain career paths to languages could be an effective tool to convince students to enroll in a language program. For example, Brenden saw the use of his language for the games/programming industry, El saw a benefit for her future career in law, Alicia and Alexander in Engineering, Tucker in business, and Bill in supply chain management. These students saw how a career in 
their field would be improved by having knowledge of a certain language. If institutions were to make this connection clear, it may lead more students to also see the career benefit of adding a language.

A solution that increases foreign language enrollment and also makes languages directly applicable to students' future careers is dual-degree programs. This has been a modern trend that is having a great impact on increasing enrollment (Redden, 2017). In these programs, students major in the field of their choice, i.e. engineering or business, along with a foreign language. Such programs allow students to study abroad or have internships abroad, where they gain interdisciplinary skills in their field in another country. This is a shift from the traditional model of foreign language programs called language-literature, which offer introductory grammar courses, followed by literature courses (Redden, 2017). Dual degree programs instead offer deep, relevant immersion inclusive of overt intention to create a global citizen.

A 2007 report from the Modern Language Association warned universities of foreign languages' waning relevance and called for a complete restructuring of language programs (Redden, 2017). They urged departments to restructure away from a language-literature program and adopt interdisciplinary and dual-degree programs that prepared students for a wide-range of careers in which they could apply their language knowledge. Based on a 2017 survey, only 39\% of faculty and administrators had since been working to change their curriculum to fit this model, suggesting that universities are largely still providing students with outdated language instruction (Redden, 2017). In the following section, I will discuss ideas instructors can implement to help motivate students to continue in foreign languages. 


\section{Recommendations to Instructors}

Many of the factors that affect the students' motivation are ones that can be influenced by the instructor. If this influence is ignored or overlooked, it can be negative because the instructor may be unintentionally demotivating their students, or they may unnecessarily be putting blame on the students for not being motivated. However, it can also be extremely positive when the instructor takes steps to ensure they are supporting and encouraging their students in a manner that does indeed motivate them. Sometimes an instructor may think they are encouraging their students but there may be ways to make it more effective.

The first issue I will address is the time commitment and how discontinuing students felt they could not keep up with the work required. I do not recommend decreasing the amount but rather reevaluating the work assigned to ensure they are meaningful tasks that are challenging yet achievable and that will also help students progress. As previously noted, students are motivated when they are able to accomplish challenging tasks (Tsang, 2012) For example, Brenden felt that he studied so many vocabulary words for a quiz that he simply forgot them right away. If what he studied outside of class were reinforced in class and were an achievable amount, he would not have felt as overwhelmed and would have been able to keep up and continue studying Japanese. He had a large amount of work to study for each class; however, because it was just to learn to pass the test, it was not reinforced or retained. Additionally, I recommend leaving class time for work that cannot be done outside of class, such as conversation activities, and having homework assignments be work that 
should not be done in class, such as reading grammar explanations or assignments that rely on English. When class time is used for application of the material and students prepare for that application in class, it offers more time for critical thinking (DeRuisseau, 2016). Next, I will discuss ways to help increase student confidence, gain an identity as a multilingual person, and have a sense of making meaningful progress.

In order to increase student confidence in their ability and help them gain and/or keep their identity as a multilingual person, instructors can help show them they are capable of becoming multilingual by showing them their progress. This can be done in a variety of ways. The continuing students often started their language studies unsure of their ability to learn a language, once they saw their progress and saw examples of multilingual Americans, they saw that they too were capable of such progress. Instructors can adjust their teaching approaches to increase the students' sense of success and progress, for example, giving positive feedback to highlight progress the students have made. Instructors may be used to only highlighting the errors for the students to correct; however, this emphasizes their faults as opposed to their successes. When editing a paper, for example, do not only mark the errors but describe and take note of what the students are doing well. Examples of this may be “Consistent and correct verb tenses!” or "Good word order." That way a student will not think they only make errors and are not making much progress. Seeing what they are doing correctly will highlight what they have learned so far and they will know their effort in certain areas is showing. 
Highlighting specific positive aspects about the process that led them to succeed will encourage them to do those more because they will understand why they did a good job (Dweck, 2006). This should not be done in the form of generalized complements based on intelligence, such as "You're such a good language learner" or "Your French is so good!" but rather as specific encouragement based on their effort such as "I see you studied the verb tenses!" or "Great job staying in German when doing partner work!" When praise and encouragement are based on the students' ability, they do not want to try anything new that may exhibit their flaws, but when students are praised based on effort, they are more likely to take on new challenges that will help them learn (Dweck, 2006). This can be used in the language classroom to help motivate and encourage students to keep practicing the language even if they make mistakes.

To highlight the progress students have made, it is also advisable to not only point this out in assignments but also during class time. To show students that they have learned something and made progress within a class period, write the goals for the period on the board and at the end ask the students if they achieved them all. For example, the goal of a lesson may be to talk about hobbies or activities that you and others like to do. On the board, you may write "Say what I like to do ( $1{ }^{\text {st }}$ person). Ask what someone likes to do ( $2^{\text {nd }}$ person). Say what someone else likes to do $\left(3^{\text {rd }}\right.$ person)." These goals should be concise and realistic. If you have structured class time in a manner that allows them to produce the material multiple times, they should all be able to achieve these goals. Being able to check these off at the end of the lesson will help the students feel that the time was worthwhile and that they made progress. 
Instructors who are interested in retaining more students can take these issues regarding student progress and adjust them according to their class. For example, Alexander was unsure about continuing until his professor made it clear to him how well he was doing in class and how much progress he had made. Giving a personal touch and discussing the students' progress while meeting with them is a simple way the instructor can ensure the students know they have made progress. It may be understandable to do this when the student has an A in class; however, it can also be done in a more strategic way when the student is not earning a high grade. For example, a student may not be doing homework or doing well on quizzes but still speaks the target language in class and tries new difficult conversations. This effort to speak in class is something that can be praised and encouraged. If students know they are making progress in some aspect of the language, they will feel encouraged and may put more effort into other areas as well. This may even take the format of midsemester evaluations where the students' progress and areas of strength can be highlighted or even in emails to the student when instructors see something they want to encourage.

In addition to giving positive feedback regarding student effort and highlighting the progress students have made, the results of this dissertation also lead to the conclusion that students need realistic and achievable tasks in order to feel meaningful progress (Dweck, 2006; Tsang, 2012). Since competence diminishes when a task is too difficult, and competence is a psychological requirement for motivation, it is advisable to assign tasks that the students are able to achieve and that give them a sense of accomplishment (Ryan et al., 2017). This is another very encouraging result 
for instructors of foreign languages because they can assist in providing opportunities for the students to use the language successfully and make strides. Notably, Tsang (2012) found that students do not have a sense of accomplishment if the task is too easy or is meaningless. Therefore, instructors should not give students unsubstantial, meaningless tasks with easily achievable goals for the sole intention of giving students a sense of accomplishment, but rather instructors should challenge them with rigorous, yet attainable goals so that when they achieve those goals, they feel that they are making meaningful, substantial progress. Next, I will discuss ways to help students push away from their identity as monolingual speakers and toward an identity of a multilingual, multicultural person.

Many of the participants described how they admired multilingual speakers and also how they did not want to be the monolingual speaker they used to be. This leads me to believe there should be as many opportunities as possible for students of foreign languages to be exposed to native speakers and international students. Meeting international people and having international experience seems to help them better reflect on their own culture and on themselves as English speakers.

Including international students as assistants or conversation partners in beginner courses could potentially give a much-needed boost to the language students' conversation abilities. A study carried out by Macaro et al., (2012) found that having bilingual assistants from the target culture helping out in the language classroom improved students' oral capabilities over a three-week period. This tactic could be used to benefit international students as well. Belkin, et al., (2016) discuss how international students frequently live with other students from their home country and 
have difficulty integrating with American students. A survey of over 450 international students in the South and Northeast showed that nearly $40 \%$ of international students had no close American friends (Gareis, 2012).

When American students can meet and converse with international students their own age in the target language and learn about the target culture, they have their own experience to construct learning from, as opposed to listening to instructors' experiences. In addition to integrating international students in their classes whenever possible, instructors may also want to help provide extracurricular activities that involve international students and language students, such as conversation groups, tandem partners, language-based movie nights, and other activities related to the target culture and language.

Cultural exposure is a specific key benefit American and international students may gain from conversations with each other in addition to being examples to one another of the kind of multilingual person they could be. While it is important for foreign language instructors to provide the students with information about the target culture, if the goal is for students to have their own personal intercultural experiences, they should be provided ways to do so. Having a student their own age tell them about their culture and language would give them first-hand experience with the target culture. They could then have a face to go with the textbook's cultural references or have a real person to compare what they may hear about the people or culture outside of class.

The final suggestions for instructors are related to connecting the language to careers. All of the continuing students and many of the non-continuing students 
mentioned a future career as a reason for wanting to learn their language. Additionally, research has shown that certain teaching methods have been shown to increase interest in having a career in that subject (Xie et al., 2014). Moreover, students are more motivated to learn the language when there is a real-life situation in which they could use the language (Allen, 2010).

Making a clear connection from language to career or major field could help students see how a language may be beneficial in their future. If the connection between careers and languages is not clear in the program design itself, the connection can be made within the course. One assignment that would make this connection clear and that would give the students autonomy is to have them do a project on how the language can be applied to their major field or future career. This could include searching for actual job or internship postings in the target country or finding ones in the United States that prefer or require language ability. Another assignment could be for the students to make their own personalized vocabulary lists of terms that are relevant to their major.

The connection between language and career can be made in a variety of other projects as well. Additional assignment idea is instead of quizzes or tests to show that students know certain aspects of grammar, they can present on a topic that relates to their major field and that actually uses the grammar being tested. An example is when learning the passive voice, students can present on or write about how a process related to their field is carried out or how a product is made. Something as simple as learning the times of day can be turned into an opportunity to further connect the language to their careers. Such as writing about or presenting on what a worker in 
their field might do on a typical day. This assignment, in particular, can be adjusted to various levels, such as a beginner level student writing on what time a worker in that field would eat lunch or get off work to an advanced level student writing about the daily tasks a worker would need to do for the job. These assignments lead them to learn specialized vocabulary for their major field, further connecting the language to their major and future career field, in addition to providing an opportunity for autonomy because they are choosing a topic that is relevant to them and relevant to their future.

\section{Table 5}

Recommendations for policy and practice

Group Recommendation

\begin{tabular}{|c|c|}
\hline College and University Administrators & 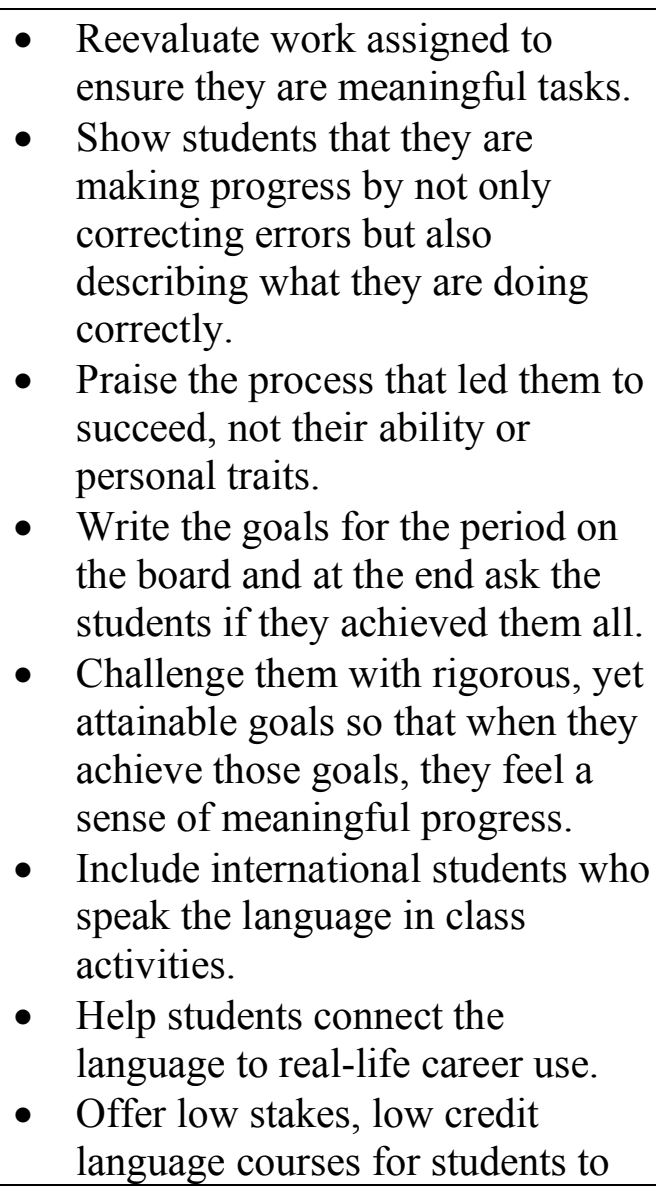 \\
\hline
\end{tabular}


stay involved without a big commitment.

- Hire international students to be classroom assistants, lead conversation groups and other campus activities or teach onecredit conversation courses.

- Provide cultural housing or living/learning communities where American and international students can live together.

- Link languages to certain majors or certain career paths in the form of dual-degree programs and/or advertising and course offerings.

- Emphasize (or require) proficiency as opposed to credits of a language.

\section{Future Research}

This study adds to the literature on motivation in foreign languages and also points to areas in further need of study. Since this was a qualitative case-study that studied nine participants in-depth, it would be beneficial to use the results to design a quantitative study that includes a large number of participants. The results of what the participants of this study said influenced them to continue or not continue could be used to formulate a series of questions to learn if these same aspects applied to a wide range of students.

Additionally, it would be interesting to triangulate these data with interviews with instructors to look into what they see as the reasons why students continue or discontinue. Moreover, it would be interesting to interview and observe instructors to see how they work to motivate students and which of those ways are indeed effective. 
They may, for example, be doing something they think is motivating or particularly effective but is in fact not linked with students continuing.

Future projects based on this dissertation include a simple guide and suggestion sheet for instructors. This will consist of suggestions taken from the previous sections and put into a brief format. This will be beneficial because instructors can easily reference it for ideas on how to retain students and will be able to add their own suggestions based on their language, department or institution. 


\section{APPENDICES}

Appendix A: Chart of Embedded Case Study, Single-Case, Multiple Units of Analysis

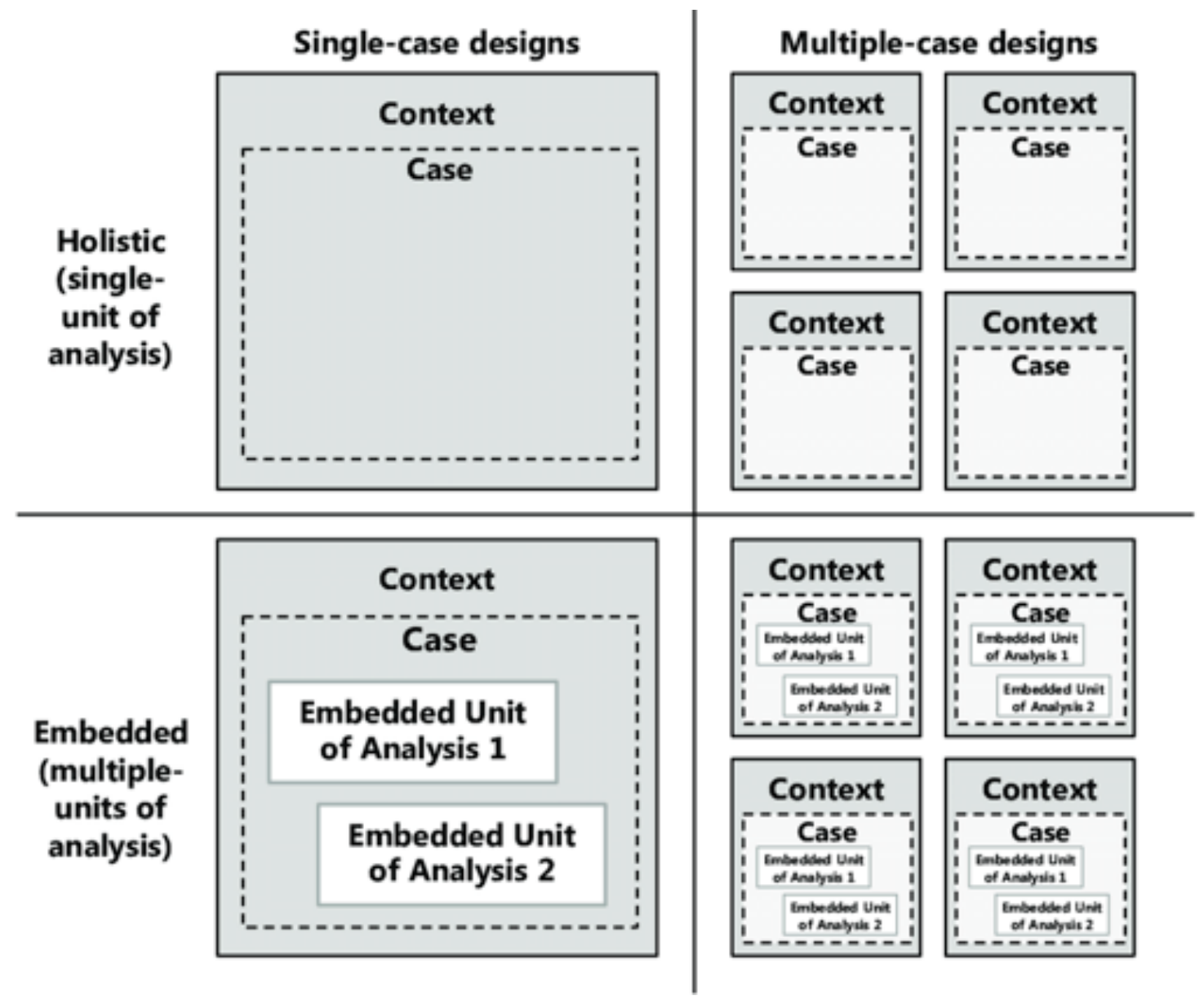




\section{Appendix B: Interview Protocol}

Answer at beginning of interview: Please write (or provide) 3 words to describe what influenced your decision to continue/not continue with languages.

Main research question: Why do some students who initially intended to only complete their major or general education foreign language requirement reconsider and decide to continue?

1. Tell me about what words you wrote down and why.

2. Tell me about the first experience(s) you had with foreign language and the perceptions you had of it at the time.

3. How did you come to study (foreign language), as opposed to other languages or another course?

4. What were your initial thoughts regarding starting a university-level (foreign language) course and how you might do?

5. What were your expectations or plans regarding studying (foreign language)?

6. Describe an experience you had that maybe changed how you regarded learning (foreign language).

7. Decision

1. If continuing: Tell me about how you made the decision to take a third semester instead of simply completing your requirements like you initially planned.

2. If not continuing: Tell me about how you made the decision not to take a third semester like you had initially planned.

8. Please fill in the blank: 
1. If continuing: I would not have continued with (foreign language) if...

2. If not continuing: I would have continued with (foreign language) if... 
Appendix C: Email to Instructors to Recruit Students In-Class

Dear

As you may know, I am a student in the URI/RIC Education PhD program. I am starting my dissertation this year and am writing you to see if you would allow me to introduce my study to your (course name) students and, if they are eligible and interested, interview them. I could visit your class (at this time). I would just need 510 minutes at the end of class.

My dissertation is on motivation in foreign language and why students may or may not continue after completing their $1^{\text {st }}$ or $2^{\text {nd }}$ semester language course. This is URI research and the purpose is to explore the experiences of beginner language students to gain insight into what occurs during their courses that influences and motivates them to continue or discontinue their language courses. The findings of this study will contribute to the pool of knowledge on practices, theory, and policy that contribute to student retention in foreign language studies.

To recruit students, I would need permission to visit your class for only 5 minutes. To make sure their participation did not affect their grade or course standing in any way, I would ask you to leave the room. While there I would introduce the study to the students and have them fill out a brief questionnaire on the students' eligibility and their interest in participating. Based on those answers I would follow up with them personally.

There are two groups of participants: those continuing and those not continuing. Qualification into the first group requires that the students are currently in their first or second language course and are registering for the following course next 
semester and that they initially intended not to continue and to only complete their major or general education course requirement of one or two semesters of a foreign language, respectively. Qualification into the second group requires that the students are currently in their first or second language course and are not registering for the following course next semester and that they initially intended to continue on to further courses after completing their major or general education course requirement of one or two semesters of a foreign language.

If students are eligible and interested in participating, I will conduct interviews with them on the URI campus. Interviews will be booked for 30-45 minutes and will take place in March, 2020.

Thank you and please feel free to email me with any questions or my Major Professor Rabia Hos at URI (rabiahos@uri.edu). The principal investigator (PI) is Rabia Hos.

This research has been approved by The University of Rhode Island Institutional Review Board

Thank you, Shawna Rambur 
Appendix D: Email to Instructors of Student Recruited Post-COVID via Email

As you may know, I am a student in the URI/RIC Education PhD program and also teach German. I am starting my dissertation this year and am writing you to see if you would forward the message below (labeled "Message to Students") to your 101 and/or 102 students to see if they are eligible and interested in participating. If they are interested there is information in their email to contact me.

My dissertation is on motivation in foreign language and why students may or may not continue after completing their $1^{\text {st }}$ or $2^{\text {nd }}$ semester language course. This is URI research and the purpose is to explore the experiences of beginner language students to gain insight into what occurs during their courses that influences and motivates them to continue or discontinue their language courses. The findings of this study will contribute to the pool of knowledge on practices, theory, and policy that contribute to student retention in foreign language studies.

There are two groups of participants; those continuing and those not continuing. Qualification into the first group requires that the students are currently in their first or second language course and are registering for the following course next semester and that they initially intended not to continue and to only complete their major or general education course requirement of one or two semesters of a foreign language, respectively. Qualification into the second group requires that the students are currently in their first or second language course and are not registering for the following course next semester and that they initially intended to continue on to 
further courses after completing their major or general education course requirement of one or two semesters of a foreign language.

If students are eligible and interested in participating, I will conduct interviews with them via web conference. Interviews will be booked for 30-45 minutes and will take place in April, 2020.

Thank you and please feel free to email me with any questions or my Major Professor Rabia Hos at URI (rabiahos@uri.edu). The principal investigator (PI) is Rabia Hos.

This research has been approved by The University of Rhode Island Institutional Review Board 
Appendix E: Email to Students Who Were Recruited Post-COVID via Email

Hi, I am Shawna Rambur, I teach German at URI and am also a doctoral student writing my dissertation on motivation in foreign language. For the dissertation study, I would like to talk with you about your choice to continue or discontinue your language studies after this semester. Interviews will be conducted via the web conference of your choice (Google Hangouts, Facetime, WebEx...etc). Please see qualifications below. If it sounds like you and you are interested, email or text me and we can set up a time to talk!

Rambur@uri.edu - 802-338-6576

This study is on motivation in foreign language and why students may or may not continue after completing their $1^{\text {st }}$ or $2^{\text {nd }}$ semester language course. This is URI research and the purpose is to explore the experiences of beginner language students to gain insight into what occurs during their courses that influences and motivates them to continue or discontinue their language courses. The findings of this study will contribute to the pool of knowledge on practices, theory, and policy that contribute to student retention in foreign language studies.

There are two groups of participants: those continuing and those not continuing.

Qualification into the first group requires that you are currently in your first or second language course and are registering for the following course next semester and that you initially intended not to continue when you first started this language. 
Qualification into the second group requires that you are currently in your first or second language course and are not registering for the following course next semester and that you initially intended to continue on to further courses when you first started this language.

Thanks!

Shawna Rambur

Principal Investigator: Rabia Hos

This research has been approved by The University of Rhode Island Institutional Review Board 


\section{Appendix F: Participant Interest Form}

Interest in participating in study on motivation in foreign language

Please indicate your eligibility and interest in participating in this study.

Participation includes being interviewed for approximately 30-45 minutes.

Interviews will take place on campus at a time when we are both available and is convenient.

1. When initially registering for your first language course, did you intend to

a) continue or b) discontinue after you met your requirements.

2. Did you change your mind about continuing/discontinuing at any point during your language courses?

Yes / No

3. What language are you studying?

4. Are you interested in participating in this study? Yes / No

If interested in participating:

In order to keep your participation anonymous, please give yourself a pseudonym. It can be any name you choose and will be how you are referred to in this study. Please also provide your phone number, if you are eligible and interested in participating I will contact you via text.

Pseudonym:

Phone number: 


\section{BIBLIOGRAPHY}

Allen, H. W. (2010). Language-Learning Motivation During Short-Term Study Abroad: An Activity Theory Perspective. Foreign Language Annals, 43(1), 2749. https://doi.org/10.1111/j.1944-9720.2010.01058.x

ACTFL Proficiency Guidelines 2012. (2012). Retrieved March 30, 2019, from https://www.actfl.org/publications/guidelines-and-manuals/actfl-proficiencyguidelines-2012

Awad, G. (2017). Motivation, Persistence, and Cross-Cultural Awareness. Academy of Educational Leadership Journal,18(4), 97-116. Retrieved May 31, 2018, from https://search-proquest-

com.uri.idm.oclc.org/docview/1645851087/fulltextPDF/DC320E5368704414P $\mathrm{Q} / 1$ ?accountid=28991

Bandura, A. (1994). Self-efficacy. In V. S. Ramachaudran (Ed.), Encyclopedia of human behavior (Vol. 4, pp. 71-81). New York: Academic Press. (Reprinted in H. Friedman [Ed.], Encyclopedia of mental health. San Diego: Academic Press, 1998).

Belkin, D., \& Jordan, M. (2016, Mar 18). Wave of Chinese hits U.S. schools, sparking discord --- colleges want international students who pay top dollar, but assimilation proves tough. Wall Street Journal Retrieved from http://uri.idm.oclc.org/login?url=https://search-proquestcom.uri.idm.oclc.org/docview/1774134759?accountid=28991

Benefits of Language Learning. (n.d.). Retrieved March 30, 2019, from 
https://www.actfl.org/guiding-principles/benefits-language-learning

Chen, H., \& Zhao, B. (2013). A Study of Interlanguage Fossilization in Second Language Acquisition and Its Teaching Implications. Proceedings of the 2013 International Conference on Educational Research and Sports Education. doi:10.2991/erse.2013.6

Creswell, J.W. (2014) Research Design. Sage Publications.

Creswell, J. W., \& Creswell, J. D. (2018). Research design: qualitative, quantitative, and mixed methods approaches (5th ed.). SAGE Publications, Inc.

Csizéer, K., and Kormos, J. (2009). Learning experiences, selves and motivated learning behavior. In Z. Dörnyei and E. Usguida (Eds.), Motivation, Language Identity and the L2 Self(pp. 98-119). Bristol: Multilingual Matters.

Curnow, T. J., \& Kohler, M. (2007). Languages are important: but that's not why I am studying one. Babel, 42(2). Retrieved from https://go-galecom.uri.idm.oclc.org/ps/i.do?p=LitRC\&u=rhode\&id=GALE $\mid A 171927213 \& v=$ 2.1\&it=r\&sid=LitRC\&asid=bba0a9bf

Deci, E. L., \& Ryan, R. M. (2008). Self-determination theory: A macrotheory of human motivation, development, and health. Canadian Psychology/Psychologie canadienne, 49(3), 182-185.

Department of Global Communications. (2020). COVID-19: UN counters pandemicrelated hate and xenophobia. Retrieved December 23, 2020, from 
https://www.un.org/en/coronavirus/covid-19-un-counters-pandemic-relatedhate-and-xenophobia

Deruisseau, L. R. (2016). The flipped classroom allows for more class time devoted to critical thinking. Advances in Physiology Education, 40(4), 522-528. doi:10.1152/advan.00033.2016

Devlin, K. (2018, August 06). Unlike in US, most European students learn a foreign language. Retrieved March 28, 2019, from https://www.pewresearch.org/facttank/2018/08/06/most-european-students-are-learning-a-foreign-language-inschool-while-americans-lag/

Dörnyei, Z. (2001). Teaching and researching motivation. Harlow: Pearson Education Limited.

Dörnyei, Z. (2005). The Psychology of the Language Learner: Individual Differences Second Language Acquisition. Lawrence Erlbaum Associates, Publishers Mahwah, N.J.

Dweck, C.S. (2006). Mindset: The New Psychology of Success. Ballantine Books. New York.

Fosnot, C. T. (Ed.). (2005). Constructivism:Theory, perspectives, and practice. New York: Teachers College Press.

Gardner, R. C. (2010). Motivation and second language acquisition: The socioeducational model. New York: Peter Lang.

Gardner,R.C.,\& Lambert,W.E. (1972). Attitudes and motivation in secondlanguage learning. Boston, MA: Newbury House Publisher. 
Gareis, E. (2012) Intercultural Friendship: Effects of Home and Host Region. Journal of International and Intercultural Communication, 5, 309-328. https://doi.org/10.1080/17513057.2012.691525

Gibson, H., \& Shutt, J. (2002). Tuning in, turning on and dropping out: an investigation into the reasons for non-completion of adult foreign language courses in colleges of FE. The Language Learning Journal, 25(1), 59-64. https://10.1080/09571730285200111.org

Gojkov-Rajić, A., \& Prtljaga, J. (2013). Foreign Language Learning as a Factor of Intercultural Tolerance. Social and Behavioral Sciences,93, 809-113. doi:https://doi.org/10.1016/j.sbspro.2013.09.284

Brett D. Jones, Sonia Llacer-Arrastia \& Paula B. Newbill (2009) Motivating foreign language students using self-determination theory, International Journal of Innovation in Language Learning and Teaching, 3:2, 171-189, DOI: $10.1080 / 17501220802358210$

Levin, B., \& Reitzel, J. D. (2018). Report to the Nation. Center for the Study of Hate \& Extremism. Retrieved August 22, 2019, from https://csbs.csusb.edu/sites/csusb_csbs/files/2018 Hate Final Report 5-14.pdf.

Litalien, D., Lüdtke, O., Parker, P., \& Trautwein, U. (2012). Different pathways, same effects: Autonomous goal regulation is associated with subjective well-being during the post-school transition. Motivation and Emotion, 37(3), 444-456.

Looney, D., \& Lusin, N. (2018, February). Enrollments in Languages Other Than English in United States Institutions of Higher Education, Summer 2016 and Fall 2016: Preliminary Report. Retrieved January 21, 2019, from 
https://www.mla.org/content/download/83540/2197676/2016-EnrollmentsShort-Report.pdf

Macaro, E., Nakatani, Y., Hayashi, Y., \& Khabbazbashi, N. (2012). Exploring the value of bilingual language assistants with Japanese English as a foreign language learners. The Language Learning Journal,42(1). doi:10.1080/09571736.2012.678275

Martin, M. D., Jansen, L., \& Beckmann, E. (2016). The Doubters Dilemma. The Australian National University. doi: 10.22459/dd.08.2016

Martinsen, R. A., Baker, W., Bown, J., \& Johnson, C. (2011). The Benefits of Living in Foreign Language Housing: The Effect of Language Use and SecondLanguage Type on Oral Proficiency Gains. The Modern Language Journal, 95(2), 274-290. doi:10.1111/j.1540-4781.2011.01180.x

Matsumoto, M. (2009). Persistence in Japanese language study and learners' cultura1/linguistic backgrounds. Australian Review of Applied Linguistics Clearing the Air, 32(2). doi: 10.2104/ara10910

Merriam, S. B. (1998). Qualitative Research and Case Study Applications in Education. San Francisco, CA: Jossey-Bass.

Miller, W. R., \& Rollnick, S. (2012). Motivational interviewing: Helping people change. New York: The Guilford Press.

Morey, B. N., Gee, G. C., Muennig, P., \& Hatzenbuehler, M. L. (2018). Communitylevel prejudice and mortality among immigrant groups. Social Science \& Medicine,199, 56-66. doi:10.1016/j.socscimed.2017.04.020 
Neuman, W. (2017, May 18). Inside Higher Ed. Retrieved March 30, 2019, from https://www.insidehighered.com/views/2017/05/18/undergraduate-foreignlanguage- requirements-arent-particularly-effective-essay

New American Economy. (2017). Not Lost in Translation: The Growing Importance of Foreign Language Skills in U.S. Job Market. Retrieved from https://urldefense.proofpoint.com/v2/url?u=http3A_research.newamericaneconomy.org_wp-

2Dcontent_uploads_2017_03_NAE-5FBilingual5FV9.pdf\&d $=$ DwIFAg\&c $=\mathrm{dWz0sRZOjEnYSN4E4J0dug \& r=YclU5e5FLqc5-}$ gV-v5qyKg\&m=cayWAKOQcIzTodqpUB44S87dW-vSLnAeFWtV$\underline{\text { MTTINE\&s=aqOFXBYdGIk0xJTn63kx6RW3R3k1611KPVwk72pMtaM\&e= }}$.

Noels, K. A. (2003). Learning Spanish as a Second Language: Learners' Orientations and Perceptions of Their Teachers' Communication Style. Language Learning, 53(S1), 97-136. https://doi.org/10.1111/1467-9922.53225

Park, H., \& Lee, A. R. (n.d.). L2 Learners' Anxiety, Self-Confidence and Oral Performance. Paal Japan. Retrieved March 17, 2017, from http://www.paaljapan.org/resources/proceedings/PAAL10/pdfs/hyesook.pdf

Patton, M. Q. (2015). Qualitative Research \& Evaluation Methods(4th ed.). Los Angeles, CA: Sage.

Racism, Xenophobia Increasing Globally, Experts Tell Third Committee, amid Calls for Laws to Combat Hate Speech, Concerns over Freedom of Expression. (2016, 
November 1). Retrieved from

https://www.un.org/press/en/2016/gashc4182.doc.htm

Ramage, K. (1990). Motivational Factors and Persistence in Foreign Language Study*. Language Learning, 40(2), 189-219. doi: 10.1111/j.14671770.1990.tb01333.x

Redden, E. (2017, January 6). Survey looks at foreign language programs' response to decade-old call to transform teaching. Retrieved March 30, 2019, from https://www.insidehighered.com/news/2017/01/06/survey-looks-foreignlanguage-programs-response-decade-old-call-transform-teaching

Reeve, J., Deci, E. L., \& Ryan, R. M. (2004). Self-Determination Theory: A Dialectical Framework for Understanding Socio-Cultural Influences on Student Motivation. In D. M. Mclnerney, \& S. Van Etten (Eds.), Big Theories Revisited (pp. 31-60). Greenwich, CT: Information Age Press.

Rousseau, J. (1979). Emile. New York: Basic Books.

Rowley, J. (2002). Using case studies in research. Management Research News,25(1). doi:10.1108/01409170210782990

Ryan, R. M., \& Deci, E. L. (2017). Self-Determination Theory. New York: The Guilford Press.

Shin, S., Lee, J.-K., \& Ha, M. (2017). Influence of Career Motivation on Science Learning in Korean High-School Students. Eurasia Journal of Mathematics, Science and Technology Education, 13(5), 1517-1538. https://doi.org/10.12973/eurasia.2017.00683a 
Tsang, S. Y. (2012). Learning Japanese as a Foreign Language in the Context of an American University: A Qualitative and Process-Oriented Study on De/Motivation at the Learning Situation Level. Foreign Language Annals,45(1), 130-163. doi:10.1111/j.19449720.2012.01167.x

Tunçel, H. (2015). The relationship between self-confidence and learning Turkish as a foreign language. Educational Research and Reviews. v10 n18 2575-2589

Von Glasersfeld, E. (1989). Cognition, Construction of Knowledge, and Teaching. Retrieved December 1, 2017, from https://www.univie.ac.at/constructivism/EvG/papers/118.pdf

Wesely, P. M. (2010). Student Attrition from Traditional and Immersion Foreign Language Programs. Language and Linguistics Compass, 4(9), 804-817. https://10.1111/j.1749-818x.2010.00241.x.org

Xie, Y., \& Reider, D. (2014). Integration of innovative technologies for enhancing students' motivation for science learning and career. Journal of Science Education and Technology, 23(3), 370-380. doi:http://dx.doi.org.uri.idm.oclc.org/10.1007/s10956-013-9469-1

Yin, R. K. (2018). Case study research and applications: Design and methods (6th ed.). Los

Angeles: Sage.

Yin, R. K. (2009). Case study research: Design and methods(4th ed.). Los Angeles: Sage 